\title{
Lack of Tgfbr1 and Acvr1b synergistically stimulates myofibre hypertrophy and
} accelerates muscle regeneration

*M.M.G. Hillege ${ }^{1}$, *A. Shi ${ }^{1,2,3}$, R.C. Galli Caro ${ }^{1}$, G. Wu ${ }^{4}$, P. Bertolino ${ }^{5}$, W.M.H. Hoogaars ${ }^{1,6}$, R.T. Jaspers ${ }^{1}$

1. Laboratory for Myology, Department of Human Movement Sciences, Faculty of Behavioural and Movement Sciences, Vrije Universiteit Amsterdam, Amsterdam Movement Sciences, Amsterdam, The Netherlands

2. Department of Oral and Maxillofacial Surgery/Pathology, Amsterdam UMC and Academic Center for Dentistry Amsterdam (ACTA), Vrije Universiteit Amsterdam (VU), Amsterdam Movement Sciences (AMS), Amsterdam, the Netherlands

3. Key Laboratory of Oral Medicine, Guangzhou Institute of Oral Disease, Affiliated Stomatology Hospital of Guangzhou Medical University, Guangzhou Medical University, Guangzhou, China

4. Department of Oral Implantology and Prosthetic Dentistry, Academic Centre for Dentistry Amsterdam (ACTA), University of Amsterdam (UvA) and Vrije Universiteit Amsterdam (VU), The Netherlands

5. Centre de Recherche en Cancérologie de Lyon, UMR INSERM U1052/CNRS 5286, Université de Lyon, Centre Léon Bérard, Lyon, France

6. European Research Institute for the Biology of Ageing (ERIBA), University Medical Center Groningen (UMCG), University of Groningen, Groningen, The Netherlands

\footnotetext{
*Contributed equally to this manuscript

**Correspondence: r.t.jaspers@vu.nl; Tel.: +31 (0) 205988463
} 


\begin{abstract}
TGF- $\beta$, myostatin and activin A are involved in regulation of muscle mass and contribute to the progressive pathology of muscle wasting disorders by regulating muscle fibrosis and inhibiting satellite cell proliferation and differentiation. Inhibition of TGF- $\beta$ signalling through knockout of TGF- $\beta$ type I receptors $T g f b r l$ and $A c v r l b$ may be a promising therapeutic approach. Here we show how muscle morphology and early muscle regeneration are altered in a myofibre specific knockout of $T g f b r 1$ and/or Acvrlb.

Simultaneous receptor knockout caused nearly doubling of tibialis anterior muscle size via a reduction in protein degradation via E3 ligases and increased phosphorylation of Akt and p70S6K, while the number of myonuclei remained unaltered. Four days post injury, CSA of regenerating myofibres lacking both receptors was substantially increased compared to that of fibres lacking either Tgfbrl or Acvrlb. This was accompanied by an increased number of satellite cells at day 0 and increased myogenic gene expression. ECM gene expression was exclusively elevated in muscle with combined receptor knockout. These findings indicate simultaneous Tgfbrl and Acvrlb knockout results in sizable muscle hypertrophy and accelerates early muscle regeneration.
\end{abstract}

Key words: TGF- $\beta$; Myostatin; Type I receptor; Cardiotoxin; Injury; Inflammation; Fibrosis 


\section{Introduction}

Muscle wasting disorders, such as muscular dystrophies, cancer cachexia and sarcopenia are characterised by reduced muscle mass, impaired regeneration and fibrosis, which results in progressive muscle weakness. The transforming growth factor $\beta$ (TGF- $\beta$ ) superfamily members TGF- $\beta 1$, myostatin and activin A are involved in various processes within muscle tissue and overexpression of these proteins contributes to muscle wasting pathologies (Bernasconi, Torchiana et al., 1995, Carlson, Hsu et al., 2008, Chen, Walton et al., 2014, Costelli, Muscaritoli et al., 2008, Leger, Derave et al., 2008, Tanaka, Miyazaki et al., 1993).

TGF- $\beta$ signalling negatively affects muscle growth by both affecting satellite cells (SCs) and myofibres. TGF- $\beta 1$, myostatin and activin A inhibit myoblast differentiation (Langley, Thomas et al., 2002, Liu, Black et al., 2001, Trendelenburg, Meyer et al., 2012). Inhibition of myostatin and activin A synergistically results in muscle hypertrophy (Amirouche, Durieux et al., 2009, Chen, Walton et al., 2017, Chen et al., 2014, Latres, Mastaitis et al., 2017, McFarlane, Plummer et al., 2006, Zimmers, Davies et al., 2002). These effects are at least partly independent of SCs (Lee, Huynh et al., 2012). In addition, TGF- $\beta 1$ overexpression in vivo may also cause muscle atrophy (Mendias, Gumucio et al., 2012, Narola, Pandey et al., 2013).

Transient TGF- $\beta 1$ expression may play an essential role during muscle regeneration. TGF- $\beta 1$ is expressed by inflammatory cells, such as macrophages, monocytes and neutrophils as well as by fibroblasts after acute injury (Assoian, Fleurdelys et al., 1987, Grotendorst, Smale et al., 1989, Lawrence, Pircher et al., 1984, Zimowska, Duchesnay et al., 2009). During muscle regeneration, TGF- $\beta 1$ is involved in the regulation of the immune response and plays an important role in rebuilding extracellular matrix (ECM) (Gillies \& Lieber, 2011, Kehrl, Wakefield et al., 1986, Reibman, Meixler et al., 1991, Tsunawaki, Sporn et al., 1988, Wahl, Hunt et al., 1987, Wiseman, Polverini et al., 1988). However, chronic 
increased expression of TGF- $\beta$ is known to contribute to muscle fibrosis (Li, Foster et al., 2004). Furthermore, myostatin and activin A have also been suggested to induce substantial skeletal muscle fibrosis (Chen et al., 2014, Li, Kollias et al., 2008). Thus, inhibition of TGF- $\beta$ signalling in the myofibre may substantially reduce connective tissue deposition.

In animal models, such as murine X-linked muscular dystrophy (mdx) mice, a DMD mouse model, cancer cachexia mouse models or aged mice, inhibiting signalling of one or more of these ligands had beneficial effects, such as reduction in fibrosis and maintenance of muscle mass (Andreetta, Bernasconi et al., 2006, Chen et al., 2017, Greco, Tomkotter et al., 2015, Latres, Pangilinan et al., 2015, Murphy, Chee et al., 2011). Lack of either TGF- $\beta$ or myostatin has been suggested to improve regeneration after acute injury (Accornero, Kanisicak et al., 2014, McCroskery, Thomas et al., 2005). Therefore, inhibiting these growth factors may be a promising therapeutic strategy to alleviate muscle wasting pathologies.

However, interference with signalling of TGF- $\beta$ family members may be complicated. TGF- $\beta$ family members regulate various cellular processes throughout the body, thus systemic inhibition of these growth factors may have severe consequences. Furthermore, due to overlap in function of these ligands, inhibition of a single ligand is likely not effective.

Simultaneous inhibition of TGF- $\beta 1$, myostatin and activin A through interference with their downstream receptors may be an effective approach. The TGF- $\beta$ family consists of at least 33 cytokines that can roughly be divided into the TGF- $\beta$ /myostatin/activins subgroup and the GDF/BMP group that often have opposing effects. These cytokines regulate gene expression via specific binding to distinct type II and type I receptors. TGF- $\beta 1$ mainly signals via the type II receptor, TGF- $\beta$ receptor type-2 (TGFBR2), and via the type I receptor, TGF- $\beta$ receptor type-1 (TGFBR1 or ALK5). Myostatin signals via the type II receptor, activin receptor type-2B (ACVR2B), and activin A signals via type II receptors, activin receptor type-2A (ACVR2A) and ACVR2B. Activin A signals via type I receptor, activin receptor 
type-1B (ACVR1B or ALK4). Myostatin has been shown to signal via both TGFBR1 and ACVR1B in various cell types (Kemaladewi, de Gorter et al., 2012, Rebbapragada, Benchabane et al., 2003, ten Dijke, Yamashita et al., 1994).

Interference with myostatin/activin A signalling by blocking their type II receptors ACVR2A/B may not be an appropriate strategy, since these receptors are also involved in BMP signalling, which stimulates muscle hypertrophy whereas myostatin/activin A signalling is associated with atrophy (Sartori, Gregorevic et al., 2014, Tsuchida, Nakatani et al., 2008). Moreover, interference with signalling via these receptors may cause severe side effects, such as nose and gum bleeds, as has been shown in in DMD boys treated with soluble ACVR2B (Campbell, McMillan et al., 2017). Inhibition of type I receptors TGFBR1 and ACVR1B may provide a more specific and effective approach to alleviate muscle wasting pathologies (cf. Sartori et al., 2014, Tsuchida et al., 2008). However, very little is known about the role of these receptors in the regulation of skeletal muscle mass and regeneration.

The aim of this study was to obtain insight in how myofibre specific knockout of type I receptors Tgfbrl and Acvrlb affects muscle size as well as early muscle regeneration, inflammation and collagen deposition in both intact and injured muscle. We hypothesised that individual knockout of these TGF- $\beta$ type I receptors will have marginal effects. Moreover, simultaneous inhibition of these type I receptors will substantially increase muscle size and enhance early myofibre regeneration, while attenuating fibrosis. 


\section{Results}

$\underline{A c v r l b}$ and $T g f b r l$ expression was successfully reduced after tamoxifen treatment

The aim of this study was to investigate effects of mature myofibre specific knockout of Tgfbrl and Acvrlb on muscle morphology as well as early muscle regeneration, inflammation and collagen deposition in both uninjured muscle tissue and after acute cardiotoxin (CTX) injury. For this purpose, the HSA-MCM mouse line (McCarthy, Srikuea et al., 2012b), that expresses tamoxifen (TMX) inducible Cre (MerCreMer) under a human $\alpha$ skeletal actin (HSA) promotor was cross bred with the conditional knockout Acvr1b ${ }^{\text {fl/fl }}$ (Ripoche, Gout et al., 2013) and Tgfbr1 $1^{\text {flfl }}$ (Larsson, Goumans et al., 2001) mouse lines to obtain mouse lines HSA-MCM:Acvr1b $\mathrm{b}^{\mathrm{fl} / \mathrm{fl}}$, HSA-MCM:Tgfbr1 $1^{\mathrm{fl} / \mathrm{fl}}$ and HSA-

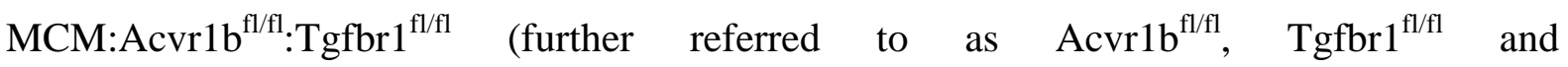

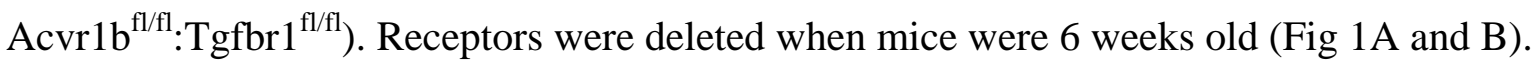

Expression levels of Acvrlb and Tgfbrl mRNA showed successful knockout as Acvrlb mRNA levels in tibialis anterior (TA) muscles were reduced in Acvr1b $\mathrm{f}^{\mathrm{fl} / \mathrm{fl}}$ animals by $97 \%$ and in Acvr1 ${ }^{\mathrm{fl} / \mathrm{fl}}:$ Tgfbr1 $1^{\mathrm{fl} / \mathrm{fl}}$ animals by $88 \%$. Tgfbrl expression levels in TA muscles were reduced in Tgfbr $1^{\mathrm{fl} / f \mathrm{l}}$ animals by $82 \%$ Unexpectedly, Tgfbrl expression levels in TA muscle of Acvr1b $b^{\mathrm{fl} / \mathrm{fl}}:$ Tgfbr $1^{\mathrm{fl} / \mathrm{fl}}$ animals were not significantly reduced compared to those of control animals (Fig 1C). Note, however, that lack of significantly reduced Tgfbrl expression is likely a consequence of high Tgfbrl expression by other cell types present within the muscle, rather than unsuccessful knockdown. Acvrlb expression levels did not affect $T g f b r l$ expression levels and vice versa.

$\underline{\text { Simultaneous knockout of } A c v r 1 b \text { and } T g f b r 1 \text { resulted in type IIB fibre hypertrophy together }}$ $\underline{\text { with a shift in fibre type distribution }}$ 
TGFBR1 and ACVR1B ligands are well known for their regulatory effects on muscle mass. Here, TA mass of Acvr1 ${ }^{\mathrm{fl} / \mathrm{fl}}:$ Tgfbr $1^{\mathrm{fl} / \mathrm{fl}}$ mice $(108.4 \pm 11.0 \mathrm{mg})$ was nearly doubled compared to that of control animals $(57.2 \pm 1.5 \mathrm{mg})$. TA mass of Tgfbr $1^{\mathrm{fl} / \mathrm{fl}}$ mice $(64.2 \pm 1.4 \mathrm{mg})$ was also increased, however to a much lower extend. TA mass of Acvr1b ${ }^{\mathrm{fl} / \mathrm{fl}}$ mice $(60.8 \pm 1.5 \mathrm{mg})$ did not differ from that of controls (Fig 1E). Average cross-sectional area (CSA) of myofibres of Acvr1 $\mathrm{b}^{\mathrm{fl} / \mathrm{fl}}$ :Tgfbr1 $1^{\mathrm{fl} / \mathrm{fl}}$ mice $\left(3989.2 \pm 313.8 \mu \mathrm{m}^{2}\right)$ was nearly twofold higher compared to that of control animals $\left(2106.3 \pm 96.0 \mu \mathrm{m}^{2}\right)$, while myofibre CSAs of Acvr1b $\mathrm{b}^{\mathrm{fl} / \mathrm{fl}}$ $\left(2003.6 \pm 101.4 \mu \mathrm{m}^{2}\right)$ and Tgfbr $1^{\mathrm{fl} / \mathrm{fl}}$ mice $\left(2270.2 \pm 96.3 \mu \mathrm{m}^{2}\right)$ did not differ (Fig 1E). These results indicate that simultaneous knockout of Acvrlb and Tgfbrl in mature mouse myofibre causes muscle hypertrophy, whereas individual knockout has little effect on muscle mass or fibre CSA.

Observed effects on myofibre CSA may indicate alterations in myofibre metabolism as well as in fibre type distribution. Therefore, fibre type distribution was determined in both the high and low oxidative region of the TA (Fig 1D and E). In the high oxidative region no significant differences were observed. However, in the low oxidative region of Acvr1 $\mathrm{b}^{\mathrm{fl} / \mathrm{fl}}:$ Tgfbr $1^{\mathrm{fl} / \mathrm{fl}}$ animals the percentage of type IIB fibres was lower $(47 \pm 2 \%)$ compared to both control $(61 \pm 2 \%)$ and Tgfbr $1^{\mathrm{flfl}}$ animals $(63 \pm 3 \%)$ (Fig 1E), which indicates a shift towards an oxidative phenotype in these muscles.

Strikingly, specifically CSA of type IIB fibres of Acvr $1 b^{\mathrm{fl} / \mathrm{fl}}:$ Tgfbr $1^{\mathrm{fl} / \mathrm{fl}}$ mice was twofold larger compared to that of control animals (Fig 1E), indicating that simultaneous knockout of both Acvrlb and Tgfbrl causes myofibre hypertrophy in type IIB myofibres.

Type IIB myofibre hypertrophy occurred without accretion of myonuclei and resulted in $\underline{\text { reduced local SDH activity }}$ 
Counts of myonuclei showed that the number of myonuclei per myofibre within IIB myofibres did not differ between control and $\operatorname{Acvr}^{\mathrm{ffl} / \mathrm{fl}}: \operatorname{Tgfbr} 1^{\mathrm{fl} / \mathrm{fl}}$ animals. The excessive hypertrophy of type IIB myofibres of Acvr $1 b^{\mathrm{fl} / \mathrm{fl}}: \operatorname{Tgfbr}^{\mathrm{fl} / \mathrm{fl}}$ mice occurred without accretion of myonuclei and caused a $70 \%$ increase in the myonuclear domain (Fig 1E).

In skeletal muscle an inverse relation exists between the myofibre size and oxidative capacity of the myofibre (Jaspers, Feenstra et al., 2006, Tseng, Kasper et al., 1994) indicating that metabolism implies a size constraint. To test whether the excessive hypertrophy was accompanied by a reduction in oxidative metabolism, within the low oxidative region of the TA muscles, succinate dehydrogenase (SDH) activity and integrated SDH activity were determined. In Acvr1b $\mathrm{b}^{\mathrm{fl} / \mathrm{fl}}$ :Tgfbr1 $1^{\mathrm{fl} / \mathrm{fl}}$ mice SDH activity was decreased by $30 \%$ compared to Acvr $1 b^{\mathrm{fl} / \mathrm{fl}}$ and control animals. However, the integrated SDH activity (total oxidative capacity of myofibres) in Acvr $1 b^{\mathrm{fl} / \mathrm{fl}}:$ Tgfbr $1^{\mathrm{fl} / \mathrm{fl}}$ mice was increased by $60 \%$ compared to control animals. This suggests that while locally the oxidative capacity in the low oxidative region of TA muscle of $A c v r 1 b^{\mathrm{fl} / \mathrm{fl}}:$ Tgfbr $1^{\mathrm{fl} / \mathrm{fl}}$ animals may be reduced, the oxidative capacity per myofibre and thus the total oxidative capacity in TA muscle of these animals was substantially increased (Fig 1E).

Myofibres with central nuclei and increased number of SCs were observed in TA muscle of $\underline{\operatorname{Acvr} 1 \mathrm{~b}^{\mathrm{fl} / \mathrm{fl}}: \text { Tgfbr }{ }^{\mathrm{fl} / \mathrm{fl}} \text { mice }}$

Hematoxylin \& Eosin (H\&E) staining and embryonic myosin heavy chain (eMyHC) staining showed within TA of uninjured Acvr1b ${ }^{\mathrm{fl} / \mathrm{fl}}$ :Tgfbr $1^{\mathrm{fl} / \mathrm{fl}}$ animals, areas with small myofibres with centrally located nuclei. These myofibres were eMyHC positive and surrounded by many other cells, likely a combination of SCs, fibroblasts and immune cells (Fig 1D). These regenerating areas were mainly present in the low oxidative region of the TA and comprised on average $2.91 \%$ of the muscle cross-section. These areas were almost never observed in TA 
of other animals $(<0.2 \%)$ (Fig $1 F)$. Together, these data indicate simultaneous knockout of Acvrlb and Tgfbrl results in spontaneous damage and regeneration. Spontaneous regeneration requires activation of SCs. In the low oxidative area of TA muscle of Acvr1 $b^{\mathrm{fl} / f \mathrm{fl}}: \operatorname{Tgfbr} 1^{\mathrm{fl} / \mathrm{fl}}$ animals the number of SCs per myofibre in a cross-section was increased compared to that in control animals (Fig 1F).

Lack of both Acvrlb and Tgfbrl in the skeletal myofibre increased $H g f$ expression levels and Akt/p70S6K signalling, while decreasing Murf-1 expression levels

Next, we aimed to obtain insight in the mechanisms underlying the increase in Acvr1 $\mathrm{b}^{\mathrm{fl} / \mathrm{fl}}: \mathrm{Tgfbr}^{\mathrm{fl} / \mathrm{fl}} \mathrm{TA}$ mass and myofibre CSA, as well as the observed increase in SC number and regeneration areas in these muscles. Since receptors were specifically knocked out in skeletal myofibres, other cell types such as SCs, fibroblasts or inflammatory cells remained sensitive to TGF- $\beta$ signalling. Therefore, the effect of receptor knockout on $T g f-\beta 1$ and myostatin $(M s t n)$ expression were determined. In TA muscles of Acvr1b ${ }^{\mathrm{fl} / \mathrm{fl}}: \mathrm{Tgfbr}^{\mathrm{fl} / \mathrm{fl}}$ animals, $T g f-\beta 1$ expression levels were 2.2-fold higher compared to those of control animals, while $T g f-\beta 1$ expression levels of Acvr $1 b^{\mathrm{fl} / f 1}$ and Tgfbr $1^{\mathrm{fl} / \mathrm{fl}}$ animals did not differ from those of control animals. Large variations of Mstn expression levels were observed within the Acvr1 $^{\mathrm{fl} / \mathrm{fl}}:$ Tgfbr $1^{\mathrm{fl} / \mathrm{fl}}$ group. As a consequence, Mstn expression levels of Acvr1b $\mathrm{b}^{\mathrm{fl} / \mathrm{fl}}: \operatorname{Tgfbr}^{\mathrm{fl} / \mathrm{fl}}$ mice were only increased compared to those of $A c v r 1 b^{\mathrm{fl} / f l}$ animals (Fig 2A). These results indicate lack of both Tgfbrl and Acvrlb in skeletal myofibres results in increased Tgf- $\beta 1$ expression in muscle tissue, which can be associated with an enhanced regeneration.

Expression levels of various growth factors, insulin-like growth factor 1Ea (Igflea), mechano growth factor $(M g f)$, fibroblast growth factor $2(F g f-2)$, hepatocyte growth factor $(H g f)$, interleukin-6 (Il-6) and vascular endothelial growth factor (Vegf) (Arsic, Zacchigna et al., 2004, Coleman, DeMayo et al., 1995, Lefaucheur \& Sebille, 1995, Pedersen, Steensberg 
et al., 2001, Serrano, Baeza-Raja et al., 2008, Tatsumi, Anderson et al., 1998, Yang \& Goldspink, 2002) may contribute to SC proliferation or myofibre size. No significant differences were observed in expression levels of Igflea, Il-6 or Fgf-2. Mgf expression levels in TA muscle of Acvr1 $\mathrm{f}^{\mathrm{fl} / \mathrm{fl}}$ :Tgfbr1 $1^{\mathrm{fl} / \mathrm{fl}}$ animals were reduced compared to those of Acvr1 $\mathrm{b}^{\mathrm{fl} / \mathrm{fl}}$ or control animals. Vegf expression levels of $A c v r 1 b^{\mathrm{fl} / f 1}: T g f b r 1^{\mathrm{fl} / \mathrm{fl}}$ animals were reduced compared to those of all other groups, while Vegf levels of Tgfbr $1^{\mathrm{fl} / f \mathrm{l}}$ animals were reduced compared to those of control animals. In contrast, $H g f$ expression levels of Acvr1b ${ }^{\mathrm{fl} / \mathrm{fl}}:$ Tgfbr $1^{\mathrm{fl} / \mathrm{fl}}$ animals were increased compared to those of all other groups (Fig 2A). These results suggest that in TA muscle of Acvr1 ${ }^{\mathrm{fl} / \mathrm{fl}}: \mathrm{Tgfbr}^{\mathrm{fl} / \mathrm{fl}}$ animals enhanced expression of $\mathrm{Hg}$ may contribute to the observed increase in SC number and hypertrophy.

Myostatin and activin A both have been shown to reduce protein synthesis by decreasing phosphorylation of Akt and its downstream target p70S6 kinase (p70S6K) (Amirouche et al., 2009, Chen et al., 2014, McFarlane et al., 2006, Trendelenburg, Meyer et al., 2009). In TA muscle of Acvr1b ${ }^{\mathrm{fl} / \mathrm{fl}}: \operatorname{Tgfbr}^{\mathrm{fl} / \mathrm{fl}}$ animals, phosphorylated Akt had increased by 2.3 -fold compared to that of control animals. A similar but insignificant trend was observed for total Akt relative intensity. No significant differences in the phosphorylated Akt/total Akt ratio were observed. However, phosphorylated p70S6K had increased by 1.9fold compared to that of control animals, while total p70S6K was not significantly affected. As a consequence, the phosphorylated p70S6K/total p70S6K was increased by 1.7-fold (Fig 2B). Together, these results indicate simultaneous knockout of Acvrlb and Tgfbrl in skeletal myofibre stimulates the protein synthesis via activation of Akt/mTOR/p70S6K signalling.

Finally, myostatin and TGF- $\beta 1$ have been indicated to stimulate muscle specific E3 ubiquitin ligases muscle RING-finger protein-1 (MuRF-1) and atrogin-1. Murf-1expression levels in TA muscles of Acvr1b $\mathrm{b}^{\mathrm{fl} / \mathrm{fl}}$ :Tgfbr $1^{\mathrm{fl} / \mathrm{fl}}$ mice were significantly lower compared to those of Acvr1b ${ }^{\mathrm{fl} / \mathrm{fl}}$ or control animals. Atrogin-1 expression did not differ between groups (Fig 2A). 
Together, these results indicate that simultaneous knockout of Acvrlb and Tgfbrl in skeletal myofibre reduces protein breakdown via suppression of Murf-1 expression.

Individual myofibre specific receptor knockout had little effect on the inflammatory response upon acute injury, while simultaneous knockout may prolong macrophage presence at the injury site

After characterisation of uninjured TA muscles, effects of receptor knockout on early TA muscle regeneration two and four days after CTX acute injury were examined. Two days post injury, the injury site was characterized by increased interstitial space, indicating degradation of the endomysium, and the presence of damaged myofibres, as can be observed as unspecific green secondary antibody staining (cf. Bencze, Periou et al., 2019). Furthermore, mononuclear cells (i.e. inflammatory cells, fibroblasts or SC) had infiltrated the interstitial space within the injury site. Together, these observations indicate that at 2 days post injury the inflammatory response is high and damaged myofibres have not started to regenerate yet. Four days post injury, the injury site was occupied by small, regenerating, eMyHC positive myofibres with centrally located nuclei. Mononuclear cells were located in the interstitial space, but the inflammatory response appears to be reduced compared to that observed at 2 days post injury (Fig 3A). No significant differences in injury size between groups were observed (Fig 3C).

Since various cell types in muscle tissue remain sensitive to TGF- $\beta$ signalling in the current model, effects of CTX injury on relative mRNA expression levels of Tgfbrl, Acvrlb, Tgf- $\beta 1$ and Mstn were examined. Two and four days post injury, relative Tgfbrl expression

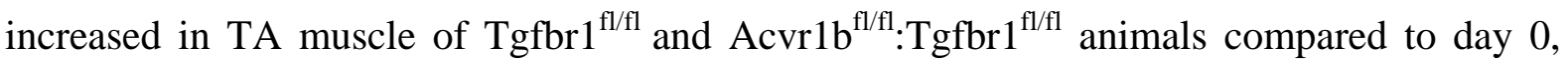
which suggests that $T g f b r l$ mRNA is highly expressed in mononuclear cells (i.e. fibroblasts, inflammation cells and SC) that infiltrate the injury site. For all groups, relative $T g f-\beta 1$ 
expression peaked at day 2 post injury. At day 4 post injury in $A c v r 1 b^{\mathrm{fl} / f 1}:$ Tgfbr $1^{\mathrm{fl} / \mathrm{fl}}$ animals, $T g f-\beta 1$ expression levels remained significantly increased compared to those of other groups (Fig 3D).

At day 2 and 4, Acvrlb expression in Tgfbr1 ${ }^{\mathrm{fl} / \mathrm{fl}}$ and control animals decreased compared to day 0, whereas Acvrlb expression in $A c v r 1 b^{\mathrm{fl} / f 1}$ and $A c v r 1 b^{\mathrm{fl} / / \mathrm{f}}:$ Tgfbr $1^{\mathrm{fl} / \mathrm{fl}}$ animals increased. Relative Mstn expression levels decreased at day 2 and 4 post injury. These data suggest that under control conditions Acvrlb and Mstn are highly expressed in skeletal myofibres, while mononuclear cells that infiltrate the injury site express relatively little Acvrlb and Mstn (Fig 3D).

TGF- $\beta 1$ plays an important role in the early inflammatory response after acute muscle injury. Inflammatory cells (i.e. neutrophils and macrophages), which infiltrate damaged muscle, digest cellular debris and secrete inflammatory cytokines, such as interleukin-1 $\beta$ (Il$1 \beta$ ) and Il-6. Here, we showed that in all groups, relative mRNA levels of macrophage specific protein cluster of differentiation $68(C d 68)$ (da Silva, Platt et al., 1996, Smith \& Koch, 1987), $I l-1 \beta$ and $I l-6$ peaked two days post injury. At day 0 and 4, in TA muscle of Acvr1 ${ }^{\mathrm{fl} / \mathrm{fl}}: \mathrm{Tgfbr}^{\mathrm{fl} / \mathrm{fl}}$ animals $C d 68$ expression was increased compared to all other groups or control animals, respectively. At day 0 and 4, macrophage specific Cd163 (Schaer, Boretti et al., 2001) expression levels of Acvr1 $\mathrm{fl}^{\mathrm{fl} / \mathrm{fl}}: \operatorname{Tgfbr}^{\mathrm{fl} / \mathrm{fl}}$ animals were increased compared to those of $A c v r 1 b^{\mathrm{fl} / f 1}$ or $T$ Tgfbr $1^{\mathrm{fl} / \mathrm{fl}}$ animals (Fig 3D). At day 0 in $A c v r 1 b^{\mathrm{fl} / \mathrm{fl}}$ :Tgfbr1 $1^{\mathrm{fl} / \mathrm{fl}}$ animals expression levels of $I l-1 \beta$ were increased compared to those of Acvr1 $\mathrm{b}^{\mathrm{fl} / f 1}$ and $\mathrm{Tgfbr} 1^{\mathrm{f} 1 / f 1}$ animals. Further, no differences in $I l-1 \beta$ and $I l-6$ expression levels were observed between groups (Fig 3D). Together, these results suggest that in this model the inflammatory response peaks approximately 2 days post injury. Skeletal myofibre specific receptor knockout has minor effects on the inflammatory response after injury. Simultaneous knockout may prolong presence of macrophages within the injured muscle tissue. 
$\underline{\text { Lack of both Acvrlb and Tgfbrl stimulated myogenic gene expression during regeneration }}$

Effects of receptor knockout on muscle regeneration after acute injury were examined (Fig 4A). Regeneration index (RI) was reduced in muscle tissue of Acvr1b $\mathrm{b}^{\mathrm{fl} / \mathrm{fl}}$ and $\mathrm{Tgfbr} 1^{\mathrm{flfl}}$ animals compared to that of control animals, while RI of Acvr1 $b^{\mathrm{fl} / \mathrm{fl}}: \operatorname{Tgfbr} 1^{\mathrm{fl} / \mathrm{fl}}$ animals was not significantly different compared to the other three groups (Fig 4B). In $\operatorname{Acvr}^{\mathrm{fl}} \mathrm{b}^{\mathrm{l} / \mathrm{f}}: \mathrm{Tgfbr}^{\mathrm{fl} / \mathrm{fl}}$ animals CSA of regenerating myofibres was increased compared to Acvr1 $b^{\mathrm{fl} / \mathrm{fl}}$ and Tgfbr1 ${ }^{\mathrm{flfl}}$ animals, but not compared to controls (Fig 4B). Taken together, after acute injury individual knockout of $A c v r l b$ or $T g f b r l$ expression in mature myofibre reduced myofibre regeneration, while simultaneous knockout of Acvrlb and Tgfbrl stimulated this.

Next, effects of receptor knockout on expression of genes involved in SC activation, differentiation and muscle growth were analysed in order to understand observed differences in RI and CSA of regenerating fibres. First of all, mRNA expression levels of various growth factors were differently affected by receptor knockout. $H g f$ and $M g f$ expression peaked at day 2 post injury. At day 2 in $A c v r 1 b^{\mathrm{fl} / f l}$ and $A c v r 1 b^{\mathrm{fl} / \mathrm{fl}}: \operatorname{Tgfbr}^{\mathrm{fl} / / \mathrm{fl}}$ mice $M g f$ expression was lower compared to control animals. At day 4 in Acvr1b ${ }^{\mathrm{fl} / \mathrm{fl}}$ :Tgfbr $1^{\mathrm{fl} / \mathrm{fl}}$ animals Igflea levels were increased compared to those of Acvr1b ${ }^{\mathrm{fl} / \mathrm{fl}}$ and control animals. Vegf and Fgf-2 expression levels decreased after injury. At day 4 in $\operatorname{Acvr}_{1 b^{\mathrm{fl} / f 1}}:$ Tgfbr $1^{\mathrm{fl} / \mathrm{fl}}$ mice $F g f-2$ expression was increased (Fig 4B). Together, these results indicate that in simultaneous receptor knockout enhanced Igflea and Fgf-2 expression up to at least 4 days post injury contribute to the accelerated early regeneration.

Proper muscle regeneration is regulated by sequential expression of myogenic genes. Thus, relative mRNA expression levels of myogenic genes (i.e., paired box protein 7 (Pax7), myoblast determination protein 1 (Myod), myogenin (Myog), muscle embryonic myosin heavy chain $(M y h 3)$ as well as inhibitor of differentiation $1(\operatorname{Idl}))$, were examined. At day 4, 
in all groups expression of Pax7, Myod, Myog and Myh3 had increased. At day 0 in

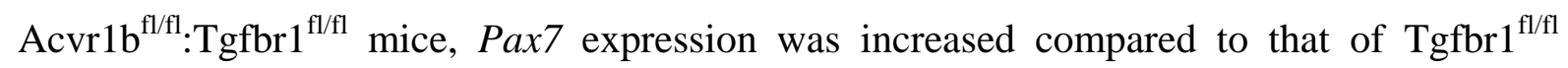
mice, while at day 4 in $A c v r 1 b^{\mathrm{fl} / / \mathrm{fl}}:$ Tgfbr $1^{\mathrm{fl} / \mathrm{fl}}$ mice $\operatorname{Pax} 7$ expression was increased compared to that in all other groups. At day 0 in $\mathrm{Acvr}^{\mathrm{ff}} \mathrm{f}^{\mathrm{l} f \mathrm{l}}: \operatorname{Tgfbr}^{\mathrm{fl} / \mathrm{fl} l}$ mice Myod and Myog expression levels were increased compared to those in other groups, while at day 2 in Acvr1b $\mathrm{b}^{\mathrm{fl} / \mathrm{fl}}:$ Tgfbr1 $1^{\mathrm{fl} / \mathrm{fl}}$ mice Myod expression levels were increased compared to those in Tgfbr $1^{\mathrm{fl} / \mathrm{fl}}$ mice and Myog expression levels were increased compared to those in both

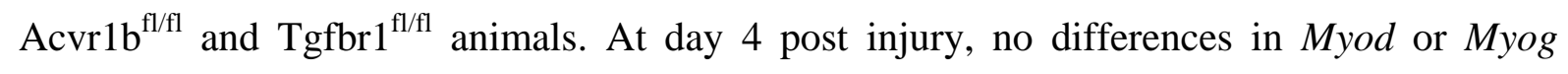
expression levels were observed between groups, although a trend suggested that expression of both genes was increased in $A c v r 1 b^{\mathrm{fl} / f 1}: \operatorname{Tgfbr}^{\mathrm{fl} / \mathrm{fl}}$ mice. At both day 0 and day 2 , in $\mathrm{Acvr} \mathrm{b}^{\mathrm{fl} / \mathrm{fl}}:$ Tgfbr $1^{\mathrm{fl} / \mathrm{fl}}$ mice $M y h 3$ levels were increased compared to those in both $A c v r 1 \mathrm{~b}^{\mathrm{fl} / \mathrm{fl}}$ and control animals. At day 4 post injury, no differences in $M y h 3$ expression were observed between groups (Fig 4B). Receptor knockout did not affect IdI expression. Taken together, these results show that in TA myofibre specific Acvrlb and Tgfbrl receptor knockout stimulates myogenic gene expression.

Lastly, relative expression levels of muscle specific E3 ligases MuRF-1 and atrogin-1 during early regeneration were considered. MuRF-1 and atrogin-1 are expressed in mature myofibres, but not in SCs and inhibit myofibre growth and hypertrophy. For Acvr1b $\mathrm{b}^{\mathrm{fl} / \mathrm{fl}}$, Tgfbr $1^{\mathrm{fl} / \mathrm{fl}}$ and control animals, at day 4 Murf- 1 levels were decreased compared to those at day 0 , while for Acvr1 $\mathrm{b}^{\mathrm{fl} / \mathrm{fl}}:$ Tgfbr $1^{\mathrm{fl} / \mathrm{fl}}$ animals no significant differences in Murf- 1 expression

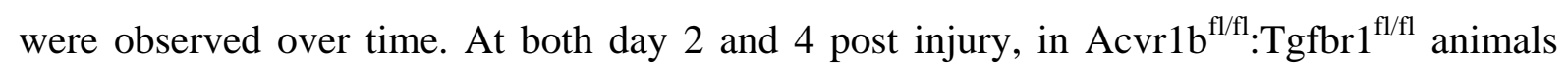
Atrogin-1 expression levels were relatively increased compared to those in Acvr1b $\mathrm{b}^{\mathrm{fl} / \mathrm{fl}}$ mice, while no differences in Murf-1 expression levels were observed between groups (Fig 4B). Together, these results indicate E3 ligases do not play a role in the observed increase in size of regenerating myofibres. 
$\underline{\text { Simultaneous knockout of both Acvrlb and Tgfbrl within the myofibre enhanced ECM }}$ deposition

Another essential aspect of muscle regeneration is connective tissue remodelling. Figure 5A shows Sirius Red stainings at different stages of regeneration. At day 0, myofibres were surrounded by a thin layer of endomysium. At 2 days post injury, this endomysium appears to be disrupted for a large part. At day 4 post injury, a large amount of connective tissue may be observed surrounding the regenerating fibres (Fig 5A).

Effects of myofibre specific Acvrlb and Tgfbrl receptor knockout on ECM remodelling were assessed by examining connective tissue growth factor $(C t g f)$, collagen type 1, alpha 1 (Collal) and collagen type 3, alpha 1 (Col3al) expression. At all times, in

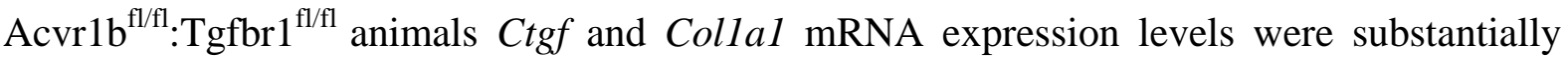
increased compared to those of control animals or all groups. At day 0 , in Acvr1b ${ }^{\mathrm{fl} / \mathrm{fl}}: \mathrm{Tgfbr}^{\mathrm{fl} / \mathrm{fl}}$ animals, Col3al expression levels were increased compared to those in other groups. At day 2 and 4, in Acvr1b $\mathrm{b}^{\mathrm{fl} / \mathrm{fl}}$ :Tgfbr $1^{\mathrm{fl} / \mathrm{fl}}$ animals Col3al expression was increased compared to Acvr1 $\mathrm{b}^{\mathrm{fl} / \mathrm{fl}}$ and Tgfbr1 $1^{\mathrm{fl} / \mathrm{fl}}$ animals (Fig 5B). Together, these data indicate that simultaneous knockout of both Acvrlb and Tgfbrl within the myofibre increases expression levels of ECM genes. 


\section{Discussion}

The aim of this study was to investigate effects of mature myofibre specific knockout of type I receptors $T g f b r l$ and $A c v r l b$ on muscle morphology as well as early muscle regeneration, inflammation and collagen deposition in both uninjured muscle tissue and after acute CTX injury. We observed that simultaneous knockout of Acvrlb and Tgfbrl resulted in a substantial increase in TA muscle mass as well as type IIB fibre CSA. Tgfbrl knockout only marginally increased TA mass, while Acvrlb knockout did not affect muscle mass. In the low oxidative region of TA muscle tissue of $A c v r 1 b^{\mathrm{fl} / f 1}: \operatorname{Tgfbr}^{\mathrm{fl} / \mathrm{fl}}$ animals the percentage of type IIB fibres was reduced. Remarkably, simultaneous knockout of both Acvrlb and Tgfbrl caused spontaneous regeneration and an increase in SC number in the low oxidative region of TA muscle tissue. Lack of both Acvrlb and Tgfbrl in the skeletal myofibre increased fibre CSA of regenerating fibres during regeneration, as well as enhanced expression levels of myogenic gene expression and growth factors. In both uninjured and regenerating muscles, simultaneous knockout of Acvrlb and Tgfbrl in the myofibre resulted in increased ECM gene transcription. Figure 6 shows a schematic summarising the main results.

Together, these results indicate that simultaneous receptor knockout stimulates muscle hypertrophy and promotes early muscle regeneration upon injury, whereas individual receptor knockout does not.

Simultaneous knockout of $A c v r l b$ and $T g f b r l$ induces hypertrophy by both inhibiting protein degradation and stimulating protein synthesis

Our data show that simultaneous myofibre specific knockdown of both Acvrlb and Tgfbrl is required for muscle hypertrophy, while inhibition of Acvrlb does not affect muscle mass or fibre size and inhibition of Tgfbrl has only marginal effects. Supporting our data, a recent study showed that simultaneous inhibition of Acvrlb and Tgfbrl was required to enhance 
muscle mass, while individual receptor inhibition had little effect (Lee, Lehar et al., 2020). These results indicate that Acvrlb and Tgfbrl have redundant functions in the regulation of muscle mass.

Myostatin and activin A negatively regulate muscle mass by stimulating protein degradation through upregulation of E3 ligases and reducing protein synthesis through a decrease in phosphorylation of Akt and its downstream target p70S6K (Amirouche et al., 2009, Chen et al., 2014, McFarlane et al., 2006, Trendelenburg et al., 2009). TGF- $\beta$ overexpression in vivo has been suggested to increase atrogin-1 expression and concomitantly cause muscle atrophy (Mendias et al., 2012). Simultaneous receptor knockout increased relative expression of phosphorylated Akt and lack of both Acvrlb and Tgfbrl increased the phosphorylated $\mathrm{p} 70 \mathrm{~S} 6 \mathrm{~K} /$ total $\mathrm{p} 70 \mathrm{~S} 6 \mathrm{~K}$ ratio, which indicates increased protein synthesis via the Akt/mTOR/p70S6K pathway contributes to muscle hypertrophy.

Simultaneous knockout of Acvrlb and Tgfbrl also reduced mRNA expression levels of E3 ligases Murf-1, indicating reduced protein degradation. Simultaneous knockout of Acvrlb and Tgfbrl increased $H g f$ expression levels. HGF signalling has been shown to protect skeletal muscle against atrophy after denervation or in muscle pathology by reducing relative Murf-1 and Atrogin-1 expression levels (Choi, Lee et al., 2018). Together, these results indicate that simultaneous knockout of both Acvrlb and Tgfbrl both decrease protein breakdown and stimulate protein synthesis.

TGF- $\beta 1$, myostatin and activin A regulate skeletal muscle mass via similar mechanisms. Previous research has shown that inhibition of myostatin and to a lesser extent activin $\mathrm{A}$ is sufficient to induce muscle hypertrophy (Chen et al., 2017). Here we show that inhibition of TGF- $\beta 1$ or activin A signalling via their type I receptor is insufficient to induce muscle hypertrophy. In muscle myostatin likely signals via both type I receptors to regulate 
muscle mass and targeting both receptors is indispensable to substantially reduce TGF$\beta 1 /$ myostatin/activin A signalling and induce muscle hypertrophy.

$\underline{\text { Simultaneous knockout of Acvrlb and Tgfbrl specifically enhances type IIB fibre CSA }}$ without accretion of myoblasts

Simultaneous knockout of $A c v r l b$ and $T g f b r l$ resulted specifically in increased type IIB fibre CSA. This is the result of fibre type-related hypertrophic capacity rather than fibre typespecific receptor knockout bias (McCarthy et al., 2012b). It has been suggested that mainly fast twitch myofibres possess the ability to hypertrophy, while slow twitch fibres are unlikely to increase in size (van Wessel, de Haan et al., 2010). Additionally, ACVR2B is more abundantly expressed in type II than type I myofibres, thus a more substantial effect on myofibre hypertrophy was expected upon type I receptor depletion (Babcock, Knoblauch et al., 2015). Remarkably, type IIB fibre hypertrophy occurred without apparent accretion of myonuclei, which resulted in an approximately $70 \%$ increase in myonuclear domain. Although e.g. exercise induced hypertrophy is often accompanied by increased myonuclei number (Conceicao, Vechin et al., 2018, van der Meer, Jaspers et al., 2011), the myonuclear domain is known to be flexible and no ceiling has been established yet (Murach, Englund et al., 2018). Moreover, inhibition of myostatin signalling using soluble ACVR2B leads to hypertrophy without accretion of SCs (Lee et al., 2012).

Since myonuclei are required for mitochondrial biogenesis, a local reduction in oxidative capacity was expected (Hock \& Kralli, 2009, Kotiadis, Duchen et al., 2014). In this study, knockout of both Acvrlb and Tgfbrl resulted in decreased SDH activity in the low oxidative area of TA. Previous research has shown that an inverse relation exists between fibre CSA and oxidative capacity, whereas fibre CSA is positively correlated to glycolytic capacity (Rivero, Talmadge et al., 1998). Recent evidence suggest that, similar to "Warburg 
effect" in tumours, in hypertrophying skeletal muscle reprogramming towards a more glycolytic metabolism occurs. Glycolytic enzyme pyruvate kinase muscle isoform 2 (PKM2), which is particularly highly expressed in type II myofibres, contributes to the increased hypertrophic potential of type II myofibres (Verbrugge, Gehlert et al., 2020).

Although lack of Acvrlb and Tgfbrl decreased SDH activity, integrated SDH activity (SDH activity per $\mu \mathrm{m}^{2}$ ) was increased. Previous research showed that integrated SDH activity is correlated to the maximal rate of oxygen consumption $\left(\mathrm{VO}_{2 \max }\right)$ and mitochondrial density, which suggests that the total oxidative capacity of these myofibres has increased (van der Laarse, Diegenbach et al., 1989). Present data show that by targeting both receptors simultaneously it is possible to deviate from the tight relation between myofibre size and oxidative metabolism. The role of both receptors in the synthesis of mitochondria warrants further investigation.

Lack of both Acvrlb and Tgfbrl reduces the percentage of type IIB fibres within the low $\underline{\text { oxidative area of the TA }}$

Another remarkable finding was the reduction in the percentage of type IIB fibres in the low oxidative region of the TA muscle of $A c v r 1 b^{\mathrm{fl} / \mathrm{fl}}$ :Tgfbr $1^{\mathrm{fl} / \mathrm{fl}}$ animals. In contrast to our findings, previous research has shown increased percentage of fast, glycolytic fibres in skeletal muscle of $\mathrm{Mstn}^{-/-}$mice (Amthor, Macharia et al., 2007, Girgenrath, Song et al., 2005, Hennebry, Berry et al., 2009). Moreover, increased myostatin/activin A signalling in follistatin mutant mice showed increased the percentage of slow, oxidative myofibres (Lee, Lee et al., 2010). Note that in a genetic knockout mouse model, absence of myostatin precedes myogenesis and may influence skeletal muscle development, whereas in our model TGF- $\beta$ signalling was inhibited in mature skeletal muscle. The reduction in type IIB fibres may also be a consequence of local damage to the myofibres, rather than a phenotypical 
change caused by receptor knockout. Taken together, these results indicate type I receptor knockout in mature myofibres has minor effects on fibre type distribution.

$\underline{\text { Simultaneous knockout of } A c v r l b \text { and Tgfbrl in myofibre may result in accelerated early }}$ $\underline{\text { regeneration }}$

We observed that simultaneous knockout of Acvrlb or Tgfbrl increased the CSA of regenerating fibres compared to individual receptor knockout, while a trend was visible compared to controls. In addition, at day 0 , simultaneous receptor knockout enhanced $\mathrm{Hg} f$ expression as well as the number of SCs per fibre and concomitantly relative expression levels of Pax7 and Myod, indicating that SCs were activated prior to CTX injection. Muscle regeneration is dependent on activation of Pax7 positive SCs and sequential expression of myogenic genes (Charge \& Rudnicki, 2004, Delaney, Kasprzycka et al., 2017, Ishido \& Kasuga, 2011, Lepper, Partridge et al., 2011). HGF is the primary growth factor for SC activation and may have accelerated early muscle regeneration (Allen, Sheehan et al., 1995, Gal-Levi, Leshem et al., 1998, Miller, Thaloor et al., 2000, Tatsumi et al., 1998). Receptor knockout did not affect $H g f$ expression after injury, which indicates HGF expression and subsequent SC activation is likely not induced by lack of TGF- $\beta$ signalling in the myofibre, but rather a consequence of spontaneous damage and regeneration.

Moreover, our data show that, though relative $F g f-2$ expression levels did not increase upon injury, four days post injury simultaneous knockout of Acvrlb and Tgfbrl increased expression levels of both Igflea and Fgf-2. Simultaneous overexpression of IGF-1 and FGF-2 has a synergistic effect on both myoblast proliferation as well as fusion index (Allen \& Boxhorn, 1989). Thus, simultaneous knockout of Acvrlb and Tgfbrl in skeletal myofibre likely enhances early muscle regeneration via enhanced expression of Igflea and Fgf-2. However, myogenic gene expression was increased prior to Igflea and Fgf-2 upregulation, 
which indicates that although these growth factors may positively contribute to early regeneration, upregulation of Igflea and Fgf-2 cannot fully explain effects on early regeneration.

Simultaneous receptor knockout did not reduce mRNA expression of E3 ligases during regeneration, indicating that the increase in fibre CSA is not caused by reduced protein breakdown. In contrast, during regeneration Atrogin-1 expression is enhanced in Acvr1 $\mathrm{fl}^{\mathrm{fl} / \mathrm{fl}}: \operatorname{Tgfbr}^{\mathrm{fl} / \mathrm{fl}}$ animals compared to other groups, but here the enhanced Atrogin-1 levels may correspond with muscle regeneration.

A limitation of this study is that we did not observe later stages of muscle regeneration. Additional research is required to determine whether changes observed in this study ultimately result in a shorter regeneration period.

\section{$\underline{A c v r l b \text { and } T g f b r l \text { have modest effects on inflammatory response after injury }}$}

Proper activation of the immune response and expression of inflammatory cytokines, such as $\mathrm{Il}-1 \beta$ and $\mathrm{Il}-6$, is important for myoblast proliferation and myogenic gene expression during early muscle regeneration (Cantini, Massimino et al., 1995, Chaweewannakorn, Tsuchiya et al., 2018, Grabiec, Tokarska et al., 2013, Zhang, Li et al., 2013). Two days post injury a large infiltration of mononucleated cells was observed in all groups, as well as a peak in relative expression levels of $T g f-\beta 1, C d 68, I l-1 \beta$ and $I l-6$.

At day 0 and 4, mRNA expression levels of $C d 68, C d 163$ and $T g f-\beta 1$ were increased by simultaneous receptor knockout. However, expression levels were low compared to the peak at day 2. Furthermore, Il-6 and $I l-1 \beta$ expression levels were not enhanced at day 2 or 4, which indicates the inflammatory response did not substantially contribute to accelerated early regeneration. The modest effects of receptor knockout on inflammatory gene expression 
indicate that the inflammatory response occurs largely independent of TGF- $\beta$ signalling within the myofibre.

Lack of both Acvrlb and Tgfbrl enhances gene expression of ECM components in both intact and injured TA muscle

In both uninjured TA muscle tissue, as well as after CTX injury simultaneous knockout of Tgfbrl and Acvrlb in skeletal myofibre increased Ctgf, Collal and Col3al mRNA expression. These increases in gene expression were conceivably caused by TGF- $\beta$ signalling in other cell types present within the muscle tissue, i.e. fibroblasts. This hypothesis is supported by the infiltration of cells that were observed in TA muscle of Acvr1 $b^{\mathrm{fl} / \mathrm{fl}}:$ Tgfbr $1^{\mathrm{fl} / \mathrm{fl}}$ animals, as well as increased expression levels of $T g f-\beta$ and Mstn. Furthermore, in Acvr1b ${ }^{\mathrm{fl} / f \mathrm{l} l}: \operatorname{Tgfbr} 1^{\mathrm{fl} / \mathrm{fl}}$ animals $T g f b r l$ levels increased after injury compared to those in groups, which indicates infiltration of cells sensitive to TGF- $\beta$ signalling. Together these results support the hypothesis that TGF- $\beta$ and myostatin act on fibroblasts and possibly other cell types within the muscle tissue to induce expression of collagens. We previously showed that inhibition of Tgfbrl in C2C12 myoblasts reduced Ctgf and Collal expression (Hillege, Galli Caro et al., 2020). Moreover, systemic administration of anti-TGF- $\beta$ or soluble ACVR2B in murine X-linked muscular dystrophy ( $\mathrm{mdx})$ mice reduced muscular fibrosis (Andreetta et al., 2006, Bo Li, Zhang et al., 2012). In conclusion, to reduce expression of ECM components within skeletal muscle inhibition of TGF- $\beta$ signalling in other cell types such as fibroblasts and satellite cells is required.

Chronic excessive ECM deposition leads to increased muscle stiffness and loss of function. However, transiently enhanced ECM deposition is essential to early muscle regeneration and results in scar free muscle repair in various types of acute injury (Hardy, Besnard et al., 2016, Mahdy, Lei et al., 2015). In this study after CTX injury Collal and 
Col3al expression increased in all groups. Transient enhanced ECM deposition is required to maintain muscle structural integrity and provides a scaffold for regenerating myofibres (Kaariainen, Jarvinen et al., 2000). Furthermore, interaction between fibroblasts and SCs appears to be essential for proper muscle regeneration, since fibroblasts prevent early differentiation of SCs, while in turn SCs control the number of fibroblasts (Murphy, Lawson et al., 2011). Thus the observed enhanced expression of ECM components in TA that lacks both receptors may contribute to the increased number of SCs at day 0 and acceleration of early muscle regeneration.

\section{$\underline{\text { Implications for ACVR1B and TGFBR1 inhibition as potential therapeutic strategy }}$}

An important limitation of our study is that we are investigating effects of Acvrlb and Tgfbrl knockout on early regeneration after an acute injury. In contrast to our model, a dystrophic or aged mouse model has characteristics such as chronic inflammation, impaired regeneration and fibrosis. Further research is required to determine how Acvrlb and Tgfbrl knockout affects long term regeneration capacity, chronic inflammation and fibrosis in a pathological model.

Our data indicate that simultaneous knockout of Acvrlb and Tgfbrl in the mature myofibre causes muscle hypertrophy and accelerates early muscle regeneration. The inflammatory response is likely independent of TGF- $\beta$ signalling within the myofibre. Furthermore, specifically targeting $T g f b r l$ and $A c v r l b$ in mature myofibre actually increased relative ECM gene expression levels. This effect is likely the result of enhanced TGF- $\beta$ signalling in other cell types (i.e. fibroblasts and inflammatory cells). Thus, targeting TGF- $\beta$ signalling in immune cells and fibroblasts present in muscle tissue is likely required to alleviate chronic inflammation and fibrosis. 
bioRxiv preprint doi: https://doi.org/10.1101/2021.03.03.433740; this version posted March 6, 2021. The copyright holder for this preprint (which was not certified by peer review) is the author/funder. All rights reserved. No reuse allowed without permission.

Taken together, our data indicate that individually inhibiting either Acvrlb or Tgfbrl may not be sufficient to alleviate muscle pathologies, nevertheless combined inhibition of both Acvrlb and Tgfbrl may increase muscle mass and accelerate early muscle regeneration. 


\section{Materials and Methods}

\section{$\underline{\text { Animal housing and welfare }}$}

The HSA-MCM transgenic mouse line (McCarthy et al., 2012b) was obtained from Jackson Laboratory, Bar Harbor, ME,USA (stock number \# 025750), the Acvr1b ${ }^{\mathrm{fl} / \mathrm{fl}}$ mouse line (Ripoche et al., 2013) was obtained from Philippe Bertolino (Cancer Research Center of Lyon, French Institute of Health and Medical Research) and the Tgfbr $1^{\mathrm{fl} / \mathrm{fl}}$ mouse line (Larsson et al., 2001) was provided by Peter ten Dijke (Leiden University Medical Center). All mouse lines were of a C57BL/6 background. Mouse lines were cross-bred in house to obtain mouse lines HSA-MCM:Acvr1b $\mathrm{f}^{\mathrm{fl} / \mathrm{fl}}$, HSA-MCM:Tgfbr1 $1^{\mathrm{fl} / \mathrm{fl}}$ and HSAMCM:Acvr1b $\mathrm{b}^{\mathrm{fl} / \mathrm{fl}}: \mathrm{Tgfbr}^{\mathrm{fl} / \mathrm{fl}}$. Animals were housed in a controlled 12 hours light-dark cycle (light on 6:00-18:00 GMT $+1 \mathrm{~h}$ ) with a temperature of $21 \pm 1{ }^{\circ} \mathrm{C}$ and a humidity between 40 and 70\%. Food (Teklad, Envigo, Horst, The Netherlands) and water were available at libitum. All experiments were performed according to the national guidelines approved by the Central Committee for Animal Experiments (CCD) (AVD112002017862) and the Institute of Animal Welfare (IvD) of the Vrije Universiteit Amsterdam.

\section{Genotyping}

In these mouse models, skeletal myofibre specific Cre expression is driven by the HAS promoter which can be activated by TMX, resulting in the deletion of targeted exon of 5 and 6 of $A c v r l b$ and exon 3 of Tgfbrl resulting in a targeted knockout of the gene. Genotyping for the HSA-MCM, Acvr1b $b^{\mathrm{fl} / \mathrm{fl}}$ and Tgfbr $1^{\mathrm{fl} / \mathrm{fl}}$ genes was performed by isolating DNA from ear biopsies of offspring and PCR was performed in a 2720 thermal cycler (Applied Biosystems, Foster City, CA, USA). PCR master mix per sample was prepared by mixing 0.2 $\mu \mathrm{l}$ of AmpliTaq Gold DNA polymerase, $2.5 \mu \mathrm{l}$ of gold buffer, $1.5 \mu \mathrm{l}$ of $\mathrm{MgCl}_{2}$ (Thermo Fisher Scientific, 4311806, Waltham, MA, USA), $0.5 \mu \mathrm{l}$ of dNTPs (100mM diluted 10x, 
Invitrogen 10297018, Carlsbad, CA, USA), $1 \mu \mathrm{l}$ of each primer diluted in DNAse/RNAse free water to obtain a volume of $23 \mu \mathrm{l}$ Master mix per sample. $2 \mu \mathrm{l}$ DNA was added per sample. The following PCR programs were used: for HSA-MCM and $A c v r 1 b^{\mathrm{fl} / \mathrm{fl}}: 94^{\circ} \mathrm{C}$ for 5 minutes, followed by a $35 \times$ cycle of $94^{\circ} \mathrm{C}$ for 30 seconds, $58^{\circ} \mathrm{C}$ for 30 seconds and $72^{\circ} \mathrm{C}$ for 10 minutes, finishing with $72^{\circ} \mathrm{C}$ for 10 minutes and cooled down to $4^{\circ} \mathrm{C}$. PCR program for Tgfbr $1^{\mathrm{fl} / \mathrm{fl}}: 94^{\circ} \mathrm{C}$ for 4 minutes, followed by a $35 \times$ cycle of $94^{\circ} \mathrm{C}$ for 30 seconds, $50^{\circ} \mathrm{C}$ for 45 seconds and $72{ }^{\circ} \mathrm{C}$ for 1 minute, finishing with $72^{\circ} \mathrm{C}$ for 5 minutes and cooled down to $4{ }^{\circ} \mathrm{C}$. Amplified DNA was mixed with $5 \mu$ l loading buffer and samples were loaded in a $4 \%$ agarose gel using SYBR safe DNA gel staining 1000× concentrate (Thermo Fisher Scientific s33102, Waltham, MA, USA), DNA was separated by electrophoresis (25 minutes, 75 V) and gel image was taken using an Image Quant LAS 500 chemo luminescence CCD camera (GE healthcare, life sciences, Chicago, IL, USA).

Primer sequences: HSA-MCM gene: Forward, 5'- GCATGGTGGAGATCTTTGA-3' (McCarthy et al., 2012b) and Reverse, 5'-CGACCGGCAAACGGACAGAAGC-'3 (McCarthy, Srikuea et al., 2012a). Acvr1b fl/fl gene: Acvr1b In4, 5'CAGTGGTTAAGAACACTGGC-3', Acvr1b In5, 5'- GTAGTGTTATGTGTTATTGCC -3' And Acvr1b In6, 5'GAGCAAGAGTTTCTCTATGTAG-3' (Ripoche et al., 2013). Tgfbr1 ${ }^{\mathrm{fl} / \mathrm{fl}}$ gene: Forward , 5'- CCTGCAGTAAACTTGGAATAAGAAG-'3, reverse, 5'GACCATCAGCTGTCAGTACCC-3' (Protocol 19216: Standard PCR Assay Tgfbr1<tm1.1Karl>, Jackson Laboratory, Bar Harbor, ME,USA).

\section{Cardiotoxin induced injury assay}

Six weeks old HSA-MCM:Acvr1b ${ }^{\mathrm{fl} / \mathrm{fl}}$, HSA-MCM:Tgfbr $1^{\mathrm{fl} / \mathrm{fl}}$, HSAMCM:Acvr1b $\mathrm{b}^{\mathrm{fl} / \mathrm{fl}}: \mathrm{Tgfbr}^{\mathrm{fl} / \mathrm{fl}}$ and HSA-MCM Cre positive male mice were injected intraperitoneally with $100 \mathrm{mg} / \mathrm{kg} /$ day tamoxifen (Sigma-Aldrich, T5648, Saint-Louis, MO, 
USA) in sunflower oil $(10 \mathrm{mg} / \mathrm{ml})$ for five consecutive days. Five weeks post TMX injections, mice were injected intramuscularly in the TA muscles of both hind limbs with 20 $\mu$ l CTX from Naja pallida (Latoxan Laboratory, L8102, Portes les Valence, France) in phosphate buffered saline (PBS) $(10 \mu \mathrm{M})$. CTX was slowly injected $(1 \mu \mathrm{l} / \mathrm{s})$ into mid muscle belly using a Hamilton syringe with attached $34 \mathrm{G}$ needle inserted in a $15-25^{\circ}$ angle, $2-3 \mathrm{~mm}$ deep. Mice were shortly anesthetised using isoflurane $1.5-3 \%$ on a warm blanket during the injections. Mice were divided into three groups: mice that were sacrificed 2 days or 4 days post injury and mice with no CTX injection, that were sacrificed at day 0 , which functioned as a baseline control. Mice were sacrificed by cervical dislocation and TA muscles were isolated and frozen in isopentane cooled in liquid nitrogen. Each subgroup contained 5-8 mice.

\section{$\underline{\text { RNA isolation and reverse transcription }}$}

Whole TA muscle was used for RNA isolation. $50 \mathrm{mg}$ cryopreserved TA muscle was homogenised (Potter S 8533024, B. BRAUN) in $700 \mu 1$ TRI reagent (Invitrogen, 11312940, Carlsbad, CA, USA) and incubated at room temperature (RT) for 5 minutes. Samples were centrifuged for 10 minutes $\left(4^{\circ} \mathrm{C}, 12000 \mathrm{~g}\right)$. Supernatant was transferred to a new tube and 70 $\mu 1$ bromochloropropane (Sigma-Aldrich, B9673, Saint Louis, MO, USA) was added. Lysates were inverted and incubated at RT for 5 minutes and centrifuged $\left(4^{\circ} \mathrm{C}, 12000 \mathrm{~g}, 10\right.$ minutes $)$. RNA containing supernatant was transferred to a new centrifuge tube and washed with $100 \%$ ethanol 2:1. RNA was further isolated using the RiboPure RNA purification kit (Thermo Fisher Scientific, AM1924, Waltham, MA, USA). Then, 500 ng RNA and $4 \mu 1$ SuperScript VILO Mastermix (Invitrogen, 12023679, Carlsbad, CA, USA) were diluted to $20 \mu \mathrm{l}$ in RNAse free water and reverse transcription was performed in a 2720 thermal cycler (Applied 
Biosystems, Foster City, CA, USA), using the following program: 10 minutes at $25{ }^{\circ} \mathrm{C}, 60$ minutes at $42{ }^{\circ} \mathrm{C}$ and 5 minutes at $85^{\circ} \mathrm{C}$. cDNA was diluted $10 \times$ in RNAse free water.

\section{Quantitative Real Time PCR}

$5 \mu 1$ of PowerUp SYBR Green master mix (Applied Biosystems, A25742, Foster City, CA, USA), $3 \mu \mathrm{l}$ of primer mix and $2 \mu 1$ of cDNA were added in duplo in a 96 wells plate. The program ran on the Quant Studio 3 real time PCR (Applied Biosystems, Foster City, CA, USA) was 2 minutes at $50^{\circ} \mathrm{C}, 2$ minutes at $95^{\circ} \mathrm{C}, 40 \times 1$ second at $95^{\circ} \mathrm{C}$ and 30 seconds at $60^{\circ} \mathrm{C}, 15$ seconds at $95^{\circ} \mathrm{C}, 1$ minute at $60^{\circ} \mathrm{C}$ and 15 seconds at $95^{\circ} \mathrm{C}$. Geometric mean of reference genes ribosomal protein S13 (Rps13) and ribosomal protein L27 (Rpl27) was used to correct for cDNA input. The efficiency of all primers sequences (Supplementary table 1) was $>98 \%$.

\section{$\underline{\text { Western blot }}$}

Fifty $20 \mu \mathrm{m}$ cross sections of TA muscles were obtained using a cryostat microtome (Microm HM550, Thermo Fisher Scientific, Kalamazoo, MI, USA). Tissue was lysed (Potter S 8533024, B. BRAUN) in RIPA buffer (Sigma-Aldrich, R0278, Saint Louis, MO, USA) containing 1 tablet of protease inhibitor (Sigma-Aldrich, 11836153001) and 1 tablet of phosStop (Sigma-Aldrich, 04906837001) per 10ml. The total protein concentration in the lysates was determined using a Pierce BCA Protein Assay kit (Thermo Scientific, 23225). A 4-20\% Mini-PROTEAN® TGX $^{\mathrm{TM}}$ Precast Protein Gels was used. $15 \mu 1$ sample mix containing $12 \mu \mathrm{g}$ total protein and $4 \mu 1$ sample buffer $(4 \times$ Laemmli Sample Buffer, Bio-Rad, 1610747) with $10 \%$ mercaptoethanol (Bio-Rad, 1610710) was heated to $95^{\circ} \mathrm{C}$ for 5 minutes, cooled on ice and loaded onto the gel. After electrophoresis, proteins were transferred onto a polyvinylidene fluoride (PVDF) membrane (GE Healthcare, 15269894) for blotting at 80V 
for 60 minutes. The membrane was incubated for 1 hour at RT in $2 \%$ enhanced chemiluminiscence (ECL) prime blocking agent (GE Healthcare, RPN418). Membranes were incubated overnight at $4^{\circ} \mathrm{C}$ in blocking buffer (4\% bovine serum albumin (BSA) in trisbuffered saline with $0.1 \%$ Tween 20 detergent (TBST) ) with primary antibody at a dilution of 1:1000 for Phospho-AKT (Ser473) (Rabbit mAb, 4060, Cell signaling, USA) , 1:2000 for AKT (pan) (C67E7) (Rabbit mAb, 4691, Cell signaling, USA), Phospho-p70S6 Kinase (Thr389) (108D2) (Rabbit mAb, 8209, Cell signaling, USA), p70S6 Kinase (49D7) (Rabbit mAb, 2708, Cell signaling, USA) and Pan-Actin (Rabbit Ab, 4968, Cell signalig, USA). Incubation with secondary antibody, anti-Rabbit IgG-POD, at a dilution of 1:2000 (P0448, Agilent Dako, USA) was done for 1 hour at RT in blocking buffer and detection was done using ECL detection kit (RPN2235, GE Healthcare, USA). Images were taken by the ImageQuant LAS500 (GE healthcare, life sciences, USA) and relative intensity of protein bands was quantified using ImageJ (Schneider, Rasband et al., 2012). Pan-Actin was used as a loading control.

\section{$\underline{\text { Tissue cross sectioning for histological analysis }}$}

For histological analysis, $10 \mu \mathrm{m}$ thick cross-sections of TA muscles were obtained using a cryostat microtome (Microm HM550, Thermo Fisher Scientific, Kalamazoo, MI, USA), mounted on microscope slides (super frost plus, Thermo Scientific, J1800AMNZ, Landsmeer, The Netherlands) and stored at $-80^{\circ} \mathrm{C}$ for further analyses.

\section{Histochemistry staining of H\&E and Sirius Red staining}

For H\&E staining, slides with muscle sections were air dried for 10 minutes. Dried slides were then stained in Hematoxylin for 2 minutes, then washed under tap water for 15 minutes and further stained in Eosin for 1 minute. Immediately after Eosin staining, slides were rinsed 
$2 \times$ in $100 \%$ alcohol for 10 seconds and $2 \times$ in xylene for 10 minutes. Stained sections were mounted in Entellan (Merck, 107960, Darmstadt, Germany), covered with coverslip and dried overnight before analysis.

For Sirius Red staining, sections were air dried for 10 minutes at RT, then they were fixed in acetone at $-20^{\circ} \mathrm{C}$ for 10 minutes and subsequently fixed in saturated Bouin for 30 minutes at RT. Samples were stained by Sirius Red for 30 minutes and washed in $0.01 \mathrm{M}$ hydrochloric acid. Then, sections were rapidly dehydrated in $100 \%$ ethanol and xylene twice. Stained sections were mounted in Entellan, covered with coverslip and dried overnight before analysis (de Bruin, Smeulders et al., 2014).

Images were captured on a Zeiss Axioskop microscope (Carl Zeiss BV, Breda The Netherlands) with Basler camera (Basler AG, Ahrensburg, Germany) using Manual WSI scanner software (Microvisioneer) for collecting whole scan images. Regeneration area percentage at day 0 was referred to area of myofibres with central nuclei divided by total area of a whole muscle cross-section. Morphometry was performed using ImageJ software (Schneider et al., 2012).

Immunofluorescence staining of myosin heavy chain (MyHC), eMyHC and Pax7

Microscope slides with muscle sections were air dried for 10 minutes. For Pax 7 staining, sections were fixed with $4 \%$ paraformaldehyde (PFA) at RT for 10 minutes and washed in PBS-T (0.05\% Tween 20). Sections were blocked at RT with $10 \%$ normal goat serum (NGS) (Thermo Fisher Scientific, 50062Z, Waltham, MA, USA) (60 minutes for MyHC and eMyHC staining, or 30 minutes for Pax7 staining). Sections for Pax7 staining were subsequently blocked in $1 \%$ BSA in PBS for 30 minutes. Sections were incubated with primary antibodies (Supplementary table 2) in 10\% NGS (for MyHC or eMyHC) or in $0.1 \%$ BSA (Pax7) at RT for 60 minutes. Then sections were incubated in secondary antibodies 
(Supplementary table 2) in 10\% NGS for MyHC and eMyHC staining, or in $0.1 \%$ BSA for Pax7 staining at RT in the dark for 60 minutes. After this, sections were incubated in 1:50 diluted wheat germ agglutinin (WGA) (Fisher Scientific, 11590816, Pittsburgh, PA, USA) in PBS at RT for 20 minutes. Finally, slides were carefully dried and mounted with Vectashield hardset mounting medium with 4‘,6-diamidino-2-phenylindole (DAPI) (Brunschwig, H1500, Amsterdam, The Netherlands). Slides were dried overnight at $4^{\circ} \mathrm{C}$.

\section{$\underline{\text { Immunofluorescence microscopy and analysis }}$}

Images of all immunofluorescence assays were captured using a fluorescent microscope (Zeiss Axiovert 200M, Hyland Scientific, Stanwood, WA, USA) with a PCO SensiCam camera (PCO, Kelheim, Germany) using the program Slidebook 5.0 (Intelligent Imaging Innovations, Göttingen, Germany). The images were analysed using ImageJ (Schneider et al., 2012). Individual images were taken across the entire cross-section and assembled into a composite panoramic image. The inner part of the muscle tissue was referred to as high oxidative region and the outer part was referred to as low oxidative region. For fibre type analysis, 250 fibres within each part were characterised. Hybrid fibre fluorescence was assessed by fibres stained by double colours and pure fibres were determined by single colour staining (Bloemberg \& Quadrilatero, 2012). Average fibre CSA was measured in H\&E images. In both the high and low oxidative region, CSA of 25 fibres was measured per TA. To determine CSA per fibre type, CSA was measured of 30 fibres per type, or as many as were present within the tissue per TA. Within images stained for Pax7, the total number of nuclei, the number of Pax7 positive nuclei and the number of myofibres were determined in the low oxidative region of TA (5 fields per specimen). SCs were defined as Pax7 positive cells that were located between plasma and basal lamina of myofibre (Lindstrom \& Thornell, 2009). In total, an average of approximately 200 fibres was included per TA. For 
regeneration analysis, myofibre CSA measurement was performed by outlining 50 eMyHC positive fibres from three randomly chosen fields within the regenerating area in muscle cross-sections of day 4. RI was defined as the number of nuclei within eMyHC positive fibres divided by the number of eMyHC positive fibres, all eMyHC positive fibres in three randomly chosen fields $\left(1.38 \mathrm{~mm}^{2}\right.$ per field $)$ within the regenerating area were included in the analysis. To measure the number of nuclei per type IIB fibre, 100 type IIB fibers in the low oxidative area were taken into account and nuclei were considered to be myonuclei if they were located within the basal lamina. All analyses were performed at 20x magnification.

\section{$\underline{\text { SDH assay }}$}

Freshly sliced sections $(10 \mu \mathrm{m}$ thick) were air dried for 15 minutes at RT. Sections were incubated in prewarmed SDH $\left(37.5 \mathrm{mM} \mathrm{NaH} \mathrm{PO}_{4} \cdot \mathrm{H}_{2} \mathrm{O}, 37.5 \mathrm{mM} \mathrm{Na} 2 \mathrm{HPO}_{4} \cdot 2 \mathrm{H}_{2} \mathrm{O}\right.$, added acid to $\mathrm{pH} 7.6,75 \mathrm{mM}$ sodium succinate, $5 \mathrm{mM} \mathrm{NaN}_{3}, 0.5 \mathrm{~g} / 1$ tetranitroblue tetrazolium (TNBT)) medium for 10 minutes at $37^{\circ} \mathrm{C}$. Sections were rinsed 3 seconds in $0.01 \mathrm{M}$ hydrochloric acid. Then sections were rinsed for $2 \times 1$ minute in ultrapure water. Finally, sections were mounted in glycerine gelatin (Merck, 48723, Darmstadt, Germany) with coverslips and dried overnight before analysis. Images were captured by a Leica DMRB microscope (Wetzlar, Germany) with calibrated grey filters and a CCD camera (Sony XC77CE, Towada, Japan) connected to a LG-3 frame grabber (Scion, Frederick, MD, United States). The absorbances of the SDH-reaction product in the sections were determined at 660 nm using a calibrated microdensitometer and ImageJ (Schneider et al., 2012). SDH activity $\left(\Delta \mathrm{A}_{660} \cdot \mu \mathrm{m}^{-1} \cdot \mathrm{s}^{-1}\right)$ was measured by the rate of absorbance per section thickness per second $\left(\Delta \mathrm{A}_{660} /(10 \mu \mathrm{m} \times 600 \mathrm{~s})\right)$ after subtracting background activity in 5 regions in low oxidative area at $10 \times$ magnification. The integrated $\mathrm{SDH}$ activity $\left(\Delta \mathrm{A}_{660} \cdot \mu \mathrm{m} \cdot \mathrm{s}^{-1}\right)$ was defined as SDH activity $\times$ myofibre CSA. Absorbance was measured in a total of 50 myofibres per TA. 


\section{$\underline{\text { Statistical analysis }}$}

Graphs were made in Prism version 8 (GraphPad software, San Diego, CA, USA). All data were presented as mean + standard error of the mean (SEM). Statistical analysis was performed in SPSS version 26 (IBM, Amsterdam, The Netherlands). Statistical significance for multiple comparisons was determined by two-way analysis of variance (ANOVA) or three-way ANOVA. Significance was set at $P<0.05$. Data normality was tested with a Shapiro-Wilk test $(P<0.05)$. Homogeneity of variance was tested with a Levene's test $(P<$ 0.01). If necessary, data were log transformed. Post hoc Bonferroni or Games-Howell corrections were performed. If normality was violated a Kruskall Wallis test was performed.

\section{Data availability}

This study includes no data deposited in external repositories. 


\section{Acknowledgements}

This research was funded by the Prinses Beatrix Spierfonds, grant number W.OR14-17. We thank Peter ten Dijke (Leiden University Medical Center) for providing the Tgfbr $1^{\mathrm{fl} / \mathrm{fl}}$ mouse line. We thank animal caretakers of the Universitair Proefdier Centrum of the Vrije Universiteit Amsterdam and students Elke Schmitz and Bijee Visbeek for their contribution to this research.

\section{Author contributions}

Conceptualization and Methodology: M.M.G.H., A.S., R.A.G., W.M.H.H., R.T.J., P.B.

Formal Analysis: M.M.G.H., A.S.

Funding acquisition: R.T.J, W.M.H.H.

Investigation: M.M.G., A.S., R.A.G.

Resources: R.T.J., P.B., G.W.

Supervision: G.W., R.T.J., W.M.H.H.

Visualization and Writing - original draft: M.M.G.H., A.S., R.T.J.

Writing - review \& editing: M.M.G.H., A.S., R.A.G., G.W., P.B., W.M.H.H., R.T.J.

\section{Conflict of interests}

Authors declare no conflict of interests. 


\section{References}

Accornero F, Kanisicak O, Tjondrokoesoemo A, Attia AC, McNally EM, Molkentin JD (2014) Myofiber-specific inhibition of TGFbeta signaling protects skeletal muscle from injury and dystrophic disease in mice. Hum Mol Genet 23: 6903-15

Allen RE, Boxhorn LK (1989) Regulation of skeletal muscle satellite cell proliferation and differentiation by transforming growth factor-beta, insulin-like growth factor I, and fibroblast growth factor. J Cell Physiol 138: 311-5

Allen RE, Sheehan SM, Taylor RG, Kendall TL, Rice GM (1995) Hepatocyte growth factor activates quiescent skeletal muscle satellite cells in vitro. J Cell Physiol 165: 307-12

Amirouche A, Durieux AC, Banzet S, Koulmann N, Bonnefoy R, Mouret C, Bigard X, Peinnequin A, Freyssenet D (2009) Down-regulation of Akt/mammalian target of rapamycin signaling pathway in response to myostatin overexpression in skeletal muscle. Endocrinology 150: $286-94$

Amthor H, Macharia R, Navarrete R, Schuelke M, Brown SC, Otto A, Voit T, Muntoni F, Vrbova G, Partridge T, Zammit P, Bunger L, Patel K (2007) Lack of myostatin results in excessive muscle growth but impaired force generation. Proc Natl Acad Sci U S A 104: 183540

Andreetta F, Bernasconi P, Baggi F, Ferro P, Oliva L, Arnoldi E, Cornelio F, Mantegazza R, Confalonieri $\mathrm{P}$ (2006) Immunomodulation of TGF-beta 1 in mdx mouse inhibits connective tissue proliferation in diaphragm but increases inflammatory response: implications for antifibrotic therapy. J Neuroimmunol 175: 77-86

Arsic N, Zacchigna S, Zentilin L, Ramirez-Correa G, Pattarini L, Salvi A, Sinagra G, Giacca M (2004) Vascular endothelial growth factor stimulates skeletal muscle regeneration in vivo. Mol Ther 10: 844-54

Assoian RK, Fleurdelys BE, Stevenson HC, Miller PJ, Madtes DK, Raines EW, Ross R, Sporn MB (1987) Expression and secretion of type beta transforming growth factor by activated human macrophages. Proc Natl Acad Sci U S A 84: 6020-4

Babcock LW, Knoblauch M, Clarke MS (2015) The role of myostatin and activin receptor IIB in the regulation of unloading-induced myofiber type-specific skeletal muscle atrophy. $J$ Appl Physiol (1985) 119: 633-42

Bencze M, Periou B, Baba-Amer Y, Authier FJ (2019) Immunolabelling Myofiber Degeneration in Muscle Biopsies. J Vis Exp

Bernasconi P, Torchiana E, Confalonieri P, Brugnoni R, Barresi R, Mora M, Cornelio F, Morandi L, Mantegazza R (1995) Expression of transforming growth factor-beta 1 in dystrophic patient muscles correlates with fibrosis. Pathogenetic role of a fibrogenic cytokine. J Clin Invest 96: 1137-44

Bloemberg D, Quadrilatero J (2012) Rapid determination of myosin heavy chain expression in rat, mouse, and human skeletal muscle using multicolor immunofluorescence analysis. PLoS One 7: e35273

Bo Li Z, Zhang J, Wagner KR (2012) Inhibition of myostatin reverses muscle fibrosis through apoptosis. J Cell Sci 125: 3957-65

Campbell C, McMillan HJ, Mah JK, Tarnopolsky M, Selby K, McClure T, Wilson DM, Sherman ML, Escolar D, Attie KM (2017) Myostatin inhibitor ACE-031 treatment of ambulatory boys with Duchenne muscular dystrophy: Results of a randomized, placebocontrolled clinical trial. Muscle Nerve 55: 458-464

Cantini M, Massimino ML, Rapizzi E, Rossini K, Catani C, Dalla Libera L, Carraro U (1995) Human satellite cell proliferation in vitro is regulated by autocrine secretion of IL-6 stimulated by a soluble factor(s) released by activated monocytes. Biochem Biophys Res Commun 216: 49-53 
Carlson ME, Hsu M, Conboy IM (2008) Imbalance between pSmad3 and Notch induces CDK inhibitors in old muscle stem cells. Nature 454: 528-32

Charge SB, Rudnicki MA (2004) Cellular and molecular regulation of muscle regeneration. Physiol Rev 84: 209-38

Chaweewannakorn C, Tsuchiya M, Koide M, Hatakeyama H, Tanaka Y, Yoshida S, Sugawara S, Hagiwara Y, Sasaki K, Kanzaki M (2018) Roles of IL-1alpha/beta in regeneration of cardiotoxin-injured muscle and satellite cell function. Am J Physiol Regul Integr Comp Physiol 315: R90-R103

Chen JL, Walton KL, Hagg A, Colgan TD, Johnson K, Qian H, Gregorevic P, Harrison CA (2017) Specific targeting of TGF-beta family ligands demonstrates distinct roles in the regulation of muscle mass in health and disease. Proc Natl Acad Sci U S A 114: E5266E5275

Chen JL, Walton KL, Winbanks CE, Murphy KT, Thomson RE, Makanji Y, Qian H, Lynch GS, Harrison CA, Gregorevic P (2014) Elevated expression of activins promotes muscle wasting and cachexia. FASEB J 28: 1711-23

Choi W, Lee J, Lee J, Ko KR, Kim S (2018) Hepatocyte Growth Factor Regulates the miR206-HDAC4 Cascade to Control Neurogenic Muscle Atrophy following Surgical Denervation in Mice. Mol Ther Nucleic Acids 12: 568-577

Coleman ME, DeMayo F, Yin KC, Lee HM, Geske R, Montgomery C, Schwartz RJ (1995) Myogenic vector expression of insulin-like growth factor I stimulates muscle cell differentiation and myofiber hypertrophy in transgenic mice. J Biol Chem 270: 12109-16

Conceicao MS, Vechin FC, Lixandrao M, Damas F, Libardi CA, Tricoli V, Roschel H, Camera D, Ugrinowitsch C (2018) Muscle Fiber Hypertrophy and Myonuclei Addition: A Systematic Review and Meta-analysis. Med Sci Sports Exerc 50: 1385-1393

Costelli P, Muscaritoli M, Bonetto A, Penna F, Reffo P, Bossola M, Bonelli G, Doglietto GB, Baccino FM, Rossi Fanelli F (2008) Muscle myostatin signalling is enhanced in experimental cancer cachexia. Eur J Clin Invest 38: 531-8

da Silva RP, Platt N, de Villiers JS, Gordon S (1996) Membrane molecules and macrophage endocytosis: scavenger receptor and macrosialin as markers of plasma-membrane and vacuolar functions. Biochem Soc Trans 24: 220-4

de Bruin M, Smeulders MJ, Kreulen M, Huijing PA, Jaspers RT (2014) Intramuscular connective tissue differences in spastic and control muscle: a mechanical and histological study. PLoS One 9: e101038

Delaney K, Kasprzycka P, Ciemerych MA, Zimowska M (2017) The role of TGF-beta1 during skeletal muscle regeneration. Cell Biol Int 41: 706-715

Gal-Levi R, Leshem Y, Aoki S, Nakamura T, Halevy O (1998) Hepatocyte growth factor plays a dual role in regulating skeletal muscle satellite cell proliferation and differentiation. Biochim Biophys Acta 1402: 39-51

Gillies AR, Lieber RL (2011) Structure and function of the skeletal muscle extracellular matrix. Muscle Nerve 44: 318-31

Girgenrath S, Song K, Whittemore LA (2005) Loss of myostatin expression alters fiber-type distribution and expression of myosin heavy chain isoforms in slow- and fast-type skeletal muscle. Muscle Nerve 31: 34-40

Grabiec K, Tokarska J, Milewska M, Blaszczyk M, Gajewska M, Grzelkowska-Kowalczyk K (2013) Interleukin-1beta stimulates early myogenesis of mouse C2C12 myoblasts: the impact on myogenic regulatory factors, extracellular matrix components, IGF binding proteins and protein kinases. Pol J Vet Sci 16: 255-64

Greco SH, Tomkotter L, Vahle AK, Rokosh R, Avanzi A, Mahmood SK, Deutsch M, Alothman S, Alqunaibit D, Ochi A, Zambirinis C, Mohaimin T, Rendon M, Levie E, Pansari M, Torres-Hernandez A, Daley D, Barilla R, Pachter HL, Tippens D et al. (2015) TGF-beta 
Blockade Reduces Mortality and Metabolic Changes in a Validated Murine Model of Pancreatic Cancer Cachexia. PLoS One 10: e0132786

Grotendorst GR, Smale G, Pencev D (1989) Production of transforming growth factor beta by human peripheral blood monocytes and neutrophils. J Cell Physiol 140: 396-402

Hardy D, Besnard A, Latil M, Jouvion G, Briand D, Thepenier C, Pascal Q, Guguin A, Gayraud-Morel B, Cavaillon JM, Tajbakhsh S, Rocheteau P, Chretien F (2016) Comparative Study of Injury Models for Studying Muscle Regeneration in Mice. PLoS One 11: e0147198 Hennebry A, Berry C, Siriett V, O'Callaghan P, Chau L, Watson T, Sharma M, Kambadur R (2009) Myostatin regulates fiber-type composition of skeletal muscle by regulating MEF2 and MyoD gene expression. Am J Physiol Cell Physiol 296: C525-34

Hillege MMG, Galli Caro RA, Offringa C, de Wit GMJ, Jaspers RT, Hoogaars WMH (2020) TGF-beta Regulates Collagen Type I Expression in Myoblasts and Myotubes via Transient Ctgf and Fgf-2 Expression. Cells 9

Hock MB, Kralli A (2009) Transcriptional control of mitochondrial biogenesis and function. Annu Rev Physiol 71: 177-203

Ishido M, Kasuga N (2011) In situ real-time imaging of the satellite cells in rat intact and injured soleus muscles using quantum dots. Histochem Cell Biol 135: 21-6

Jaspers RT, Feenstra HM, van Beek-Harmsen BJ, Huijing PA, van der Laarse WJ (2006) Differential effects of muscle fibre length and insulin on muscle-specific mRNA content in isolated mature muscle fibres during long-term culture. Cell Tissue Res 326: 795-808

Kaariainen M, Jarvinen T, Jarvinen M, Rantanen J, Kalimo H (2000) Relation between myofibers and connective tissue during muscle injury repair. Scand J Med Sci Sports 10: 3327

Kehrl JH, Wakefield LM, Roberts AB, Jakowlew S, Alvarez-Mon M, Derynck R, Sporn MB, Fauci AS (1986) Production of transforming growth factor beta by human T lymphocytes and its potential role in the regulation of T cell growth. J Exp Med 163: 1037-50

Kemaladewi DU, de Gorter DJ, Aartsma-Rus A, van Ommen GJ, ten Dijke P, t Hoen PA, Hoogaars WM (2012) Cell-type specific regulation of myostatin signaling. FASEB J 26: 1462-72

Kotiadis VN, Duchen MR, Osellame LD (2014) Mitochondrial quality control and communications with the nucleus are important in maintaining mitochondrial function and cell health. Biochim Biophys Acta 1840: 1254-65

Langley B, Thomas M, Bishop A, Sharma M, Gilmour S, Kambadur R (2002) Myostatin inhibits myoblast differentiation by down-regulating MyoD expression. J Biol Chem 277: 49831-40

Larsson J, Goumans MJ, Sjostrand LJ, van Rooijen MA, Ward D, Leveen P, Xu X, ten Dijke P, Mummery CL, Karlsson S (2001) Abnormal angiogenesis but intact hematopoietic potential in TGF-beta type I receptor-deficient mice. EMBO J 20: 1663-73

Latres E, Mastaitis J, Fury W, Miloscio L, Trejos J, Pangilinan J, Okamoto H, Cavino K, Na E, Papatheodorou A, Willer T, Bai Y, Hae Kim J, Rafique A, Jaspers S, Stitt T, Murphy AJ, Yancopoulos GD, Gromada J (2017) Activin A more prominently regulates muscle mass in primates than does GDF8. Nat Commun 8: 15153

Latres E, Pangilinan J, Miloscio L, Bauerlein R, Na E, Potocky TB, Huang Y, Eckersdorff M, Rafique A, Mastaitis J, Lin C, Murphy AJ, Yancopoulos GD, Gromada J, Stitt T (2015) Myostatin blockade with a fully human monoclonal antibody induces muscle hypertrophy and reverses muscle atrophy in young and aged mice. Skelet Muscle 5: 34

Lawrence DA, Pircher R, Kryceve-Martinerie C, Jullien P (1984) Normal embryo fibroblasts release transforming growth factors in a latent form. J Cell Physiol 121: 184-8

Lee SJ, Huynh TV, Lee YS, Sebald SM, Wilcox-Adelman SA, Iwamori N, Lepper C, Matzuk MM, Fan CM (2012) Role of satellite cells versus myofibers in muscle hypertrophy induced 
by inhibition of the myostatin/activin signaling pathway. Proc Natl Acad Sci U S A 109: E2353-60

Lee SJ, Lee YS, Zimmers TA, Soleimani A, Matzuk MM, Tsuchida K, Cohn RD, Barton ER (2010) Regulation of muscle mass by follistatin and activins. Mol Endocrinol 24: 1998-2008

Lee SJ, Lehar A, Liu Y, Ly CH, Pham QM, Michaud M, Rydzik R, Youngstrom DW, Shen MM, Kaartinen V, Germain-Lee EL, Rando TA (2020) Functional redundancy of type I and type II receptors in the regulation of skeletal muscle growth by myostatin and activin A. Proc Natl Acad Sci U S A 117: 30907-30917

Lefaucheur JP, Sebille A (1995) Muscle regeneration following injury can be modified in vivo by immune neutralization of basic fibroblast growth factor, transforming growth factor beta 1 or insulin-like growth factor I. J Neuroimmunol 57: 85-91

Leger B, Derave W, De Bock K, Hespel P, Russell AP (2008) Human sarcopenia reveals an increase in SOCS-3 and myostatin and a reduced efficiency of Akt phosphorylation. Rejuvenation Res 11: 163-175B

Lepper C, Partridge TA, Fan CM (2011) An absolute requirement for Pax7-positive satellite cells in acute injury-induced skeletal muscle regeneration. Development 138: 3639-46

Li Y, Foster W, Deasy BM, Chan Y, Prisk V, Tang Y, Cummins J, Huard J (2004) Transforming growth factor-betal induces the differentiation of myogenic cells into fibrotic cells in injured skeletal muscle: a key event in muscle fibrogenesis. Am J Pathol 164: 100719

Li ZB, Kollias HD, Wagner KR (2008) Myostatin directly regulates skeletal muscle fibrosis. J Biol Chem 283: 19371-8

Lindstrom M, Thornell LE (2009) New multiple labelling method for improved satellite cell identification in human muscle: application to a cohort of power-lifters and sedentary men. Histochem Cell Biol 132: 141-57

Liu D, Black BL, Derynck R (2001) TGF-beta inhibits muscle differentiation through functional repression of myogenic transcription factors by Smad3. Genes Dev 15: 2950-66 Mahdy MA, Lei HY, Wakamatsu J, Hosaka YZ, Nishimura T (2015) Comparative study of muscle regeneration following cardiotoxin and glycerol injury. Ann Anat 202: 18-27

McCarthy JJ, Srikuea R, Kirby TJ, Peterson CA, Esser KA (2012a) Correction: Inducible Cre transgenic mouse strain for skeletal muscle-specific gene targeting. Skelet Muscle 2: 22

McCarthy JJ, Srikuea R, Kirby TJ, Peterson CA, Esser KA (2012b) Inducible Cre transgenic mouse strain for skeletal muscle-specific gene targeting. Skelet Muscle 2: 8

McCroskery S, Thomas M, Platt L, Hennebry A, Nishimura T, McLeay L, Sharma M, Kambadur R (2005) Improved muscle healing through enhanced regeneration and reduced fibrosis in myostatin-null mice. J Cell Sci 118: 3531-41

McFarlane C, Plummer E, Thomas M, Hennebry A, Ashby M, Ling N, Smith H, Sharma M, Kambadur R (2006) Myostatin induces cachexia by activating the ubiquitin proteolytic system through an NF-kappaB-independent, FoxO1-dependent mechanism. J Cell Physiol 209: 501-14

Mendias CL, Gumucio JP, Davis ME, Bromley CW, Davis CS, Brooks SV (2012) Transforming growth factor-beta induces skeletal muscle atrophy and fibrosis through the induction of atrogin-1 and scleraxis. Muscle Nerve 45: 55-9

Miller KJ, Thaloor D, Matteson S, Pavlath GK (2000) Hepatocyte growth factor affects satellite cell activation and differentiation in regenerating skeletal muscle. Am J Physiol Cell Physiol 278: C174-81

Murach KA, Englund DA, Dupont-Versteegden EE, McCarthy JJ, Peterson CA (2018) Myonuclear Domain Flexibility Challenges Rigid Assumptions on Satellite Cell Contribution to Skeletal Muscle Fiber Hypertrophy. Front Physiol 9: 635 
Murphy KT, Chee A, Gleeson BG, Naim T, Swiderski K, Koopman R, Lynch GS (2011) Antibody-directed myostatin inhibition enhances muscle mass and function in tumor-bearing mice. Am J Physiol Regul Integr Comp Physiol 301: R716-26

Murphy MM, Lawson JA, Mathew SJ, Hutcheson DA, Kardon G (2011) Satellite cells, connective tissue fibroblasts and their interactions are crucial for muscle regeneration. Development 138: 3625-37

Narola J, Pandey SN, Glick A, Chen YW (2013) Conditional expression of TGF-beta1 in skeletal muscles causes endomysial fibrosis and myofibers atrophy. PLoS One 8: e79356

Pedersen BK, Steensberg A, Schjerling P (2001) Exercise and interleukin-6. Curr Opin Hematol 8: 137-41

Rebbapragada A, Benchabane H, Wrana JL, Celeste AJ, Attisano L (2003) Myostatin signals through a transforming growth factor beta-like signaling pathway to block adipogenesis. $\mathrm{Mol}$ Cell Biol 23: 7230-42

Reibman J, Meixler S, Lee TC, Gold LI, Cronstein BN, Haines KA, Kolasinski SL, Weissmann G (1991) Transforming growth factor beta 1, a potent chemoattractant for human neutrophils, bypasses classic signal-transduction pathways. Proc Natl Acad Sci U S 88: 6805-9

Ripoche D, Gout J, Pommier RM, Jaafar R, Zhang CX, Bartholin L, Bertolino P (2013) Generation of a conditional mouse model to target Acvr1b disruption in adult tissues. Genesis 51: $120-7$

Rivero JL, Talmadge RJ, Edgerton VR (1998) Fibre size and metabolic properties of myosin heavy chain-based fibre types in rat skeletal muscle. J Muscle Res Cell Motil 19: 733-42

Sartori R, Gregorevic P, Sandri M (2014) TGFbeta and BMP signaling in skeletal muscle: potential significance for muscle-related disease. Trends Endocrinol Metab 25: 464-71

Schaer DJ, Boretti FS, Hongegger A, Poehler D, Linnscheid P, Staege H, Muller C, Schoedon G, Schaffner A (2001) Molecular cloning and characterization of the mouse CD163 homologue, a highly glucocorticoid-inducible member of the scavenger receptor cysteine-rich family. Immunogenetics 53: 170-7

Schneider CA, Rasband WS, Eliceiri KW (2012) NIH Image to ImageJ: 25 years of image analysis. Nat Methods 9: 671-5

Serrano AL, Baeza-Raja B, Perdiguero E, Jardi M, Munoz-Canoves P (2008) Interleukin-6 is an essential regulator of satellite cell-mediated skeletal muscle hypertrophy. Cell Metab 7: 33-44

Smith MJ, Koch GL (1987) Differential expression of murine macrophage surface glycoprotein antigens in intracellular membranes. J Cell Sci 87 ( Pt 1): 113-9

Tanaka M, Miyazaki H, Takeda Y, Takeo S (1993) Detection of serum cytokine levels in experimental cancer cachexia of colon 26 adenocarcinoma-bearing mice. Cancer Lett 72: 6570

Tatsumi R, Anderson JE, Nevoret CJ, Halevy O, Allen RE (1998) HGF/SF is present in normal adult skeletal muscle and is capable of activating satellite cells. Dev Biol 194: 114-28 ten Dijke P, Yamashita H, Ichijo H, Franzen P, Laiho M, Miyazono K, Heldin CH (1994) Characterization of type I receptors for transforming growth factor-beta and activin. Science 264: 101-4

Trendelenburg AU, Meyer A, Jacobi C, Feige JN, Glass DJ (2012) TAK-1/p38/nNFkappaB signaling inhibits myoblast differentiation by increasing levels of Activin A. Skelet Muscle 2: 3

Trendelenburg AU, Meyer A, Rohner D, Boyle J, Hatakeyama S, Glass DJ (2009) Myostatin reduces Akt/TORC1/p70S6K signaling, inhibiting myoblast differentiation and myotube size. Am J Physiol Cell Physiol 296: C1258-70 
Tseng BS, Kasper CE, Edgerton VR (1994) Cytoplasm-to-myonucleus ratios and succinate dehydrogenase activities in adult rat slow and fast muscle fibers. Cell Tissue Res 275: 39-49 Tsuchida K, Nakatani M, Uezumi A, Murakami T, Cui X (2008) Signal transduction pathway through activin receptors as a therapeutic target of musculoskeletal diseases and cancer. Endocr J 55: 11-21

Tsunawaki S, Sporn M, Ding A, Nathan C (1988) Deactivation of macrophages by transforming growth factor-beta. Nature 334: 260-2

van der Laarse WJ, Diegenbach PC, Elzinga G (1989) Maximum rate of oxygen consumption and quantitative histochemistry of succinate dehydrogenase in single muscle fibres of Xenopus laevis. J Muscle Res Cell Motil 10: 221-8

van der Meer SF, Jaspers RT, Jones DA, Degens H (2011) The time course of myonuclear accretion during hypertrophy in young adult and older rat plantaris muscle. Ann Anat 193: $56-63$

van Wessel T, de Haan A, van der Laarse WJ, Jaspers RT (2010) The muscle fiber type-fiber size paradox: hypertrophy or oxidative metabolism? Eur J Appl Physiol 110: 665-94

Verbrugge SAJ, Gehlert S, Stadhouders LEM, Jacko D, Aussieker T, G MJdW, Vogel ISP, Offringa C, Schonfelder M, Jaspers RT, Wackerhage H (2020) PKM2 Determines Myofiber Hypertrophy In Vitro and Increases in Response to Resistance Exercise in Human Skeletal Muscle. Int J Mol Sci 21

Wahl SM, Hunt DA, Wakefield LM, McCartney-Francis N, Wahl LM, Roberts AB, Sporn MB (1987) Transforming growth factor type beta induces monocyte chemotaxis and growth factor production. Proc Natl Acad Sci U S A 84: 5788-92

Wiseman DM, Polverini PJ, Kamp DW, Leibovich SJ (1988) Transforming growth factorbeta (TGF beta) is chemotactic for human monocytes and induces their expression of angiogenic activity. Biochem Biophys Res Commun 157: 793-800

Yang SY, Goldspink G (2002) Different roles of the IGF-I Ec peptide (MGF) and mature IGF-I in myoblast proliferation and differentiation. FEBS Lett 522: 156-60

Zhang C, Li Y, Wu Y, Wang L, Wang X, Du J (2013) Interleukin-6/signal transducer and activator of transcription 3 (STAT3) pathway is essential for macrophage infiltration and myoblast proliferation during muscle regeneration. J Biol Chem 288: 1489-99

Zimmers TA, Davies MV, Koniaris LG, Haynes P, Esquela AF, Tomkinson KN, McPherron AC, Wolfman NM, Lee SJ (2002) Induction of cachexia in mice by systemically administered myostatin. Science 296: 1486-8

Zimowska M, Duchesnay A, Dragun P, Oberbek A, Moraczewski J, Martelly I (2009) Immunoneutralization of TGFbeta1 Improves Skeletal Muscle Regeneration: Effects on Myoblast Differentiation and Glycosaminoglycan Content. Int J Cell Biol 2009: 659372 
Figure 1. Simultaneous knockout of both Acvrlb and Tgfbrl caused muscle hypertrophy and spontaneous regions of muscle regeneration. (A) Scheme showing cross-breeding of HSAMCM mouse line with conditional knockout mouse lines Acvr1b $\mathrm{f}^{\mathrm{fl} / \mathrm{fl}}$ and Tgfbr $1^{\mathrm{fl} / \mathrm{fl}}$. LoxP sites are indicated by black arrows. A loxP-flanked neomycin (neo) cassette is inserted upstream of exon3 of Acvr1b genome. (B) Scheme demonstrating receptor knockout induced by tamoxifen (TMX) injection for consecutive 5 days. (C) Relative mRNA expression of Acvrlb and Tgfbrl in TA muscles of experimental groups. (D) Histology stainings of TA muscles 35 day after first TMX injection. H\&E staining and immunofluorescence (IF) staining of eMyHC (green) of TA showed regenerative regions containing eMyHC positive myofibres with central nuclei (DAPI, blue) in Acvr1b $\mathrm{b}^{\mathrm{fl} / \mathrm{fl}}$ :Tgfbr $1^{\mathrm{fl} / \mathrm{fl}}$ mice, wheat glucose agglutinin (WGA, red) was used to visualise cell membranes and ECM. Acvr1b $\mathrm{b}^{\mathrm{fl} / \mathrm{fl}}: \operatorname{Tgfbr}^{\mathrm{fl} / \mathrm{fl}}$ mice showed lower staining intensity for SDH in low oxidative area of TA. IF staining of MyHCs demonstrated type IIA (green), IIB (red), I (red) and IIX (green) myofibres in low and high oxidative area of TA. WGA was stained in red (scale bars $=250 \mu \mathrm{m})$. (E) TA muscle mass and myofibre CSA were increased in TA of Acvr1b ${ }^{\mathrm{fl} / f 1}: \operatorname{Tgfbr}^{\mathrm{fl} / \mathrm{fl}}$ mice. Percentage of type IIB in low oxidative area of TA was reduced, while CSA of type IIB fibres increased in Acvr1 $\mathrm{b}^{\mathrm{fl} / \mathrm{fl}}:$ Tgfbr $1^{\mathrm{fl} / \mathrm{fl}}$ animals. Total number of nuclei per IIB myofibre did not differ between Acvr1b ${ }^{\mathrm{fl} / \mathrm{fl}}:$ Tgfbr $1^{\mathrm{fl} / \mathrm{fl}}$ and control animals. Myonuclear domain $\left(\mu \mathrm{m}^{2}\right)$ in IIB fibres of Acvr1b ${ }^{\mathrm{fl} / \mathrm{fl}}:$ Tgfbr $1^{\mathrm{fl} / \mathrm{fl}}$ mice was increased. SDH activity (absorbance units $(\Delta \mathrm{A} 660)$ per micrometer section thickness per second of incubation time $\left.\left(\Delta \mathrm{A} 660 \cdot \mu \mathrm{m}^{-1} \cdot \mathrm{s}^{-1}\right)\right)$ was decreased, while the integrated SDH activity (SDH activity multiplied by CSA $\left(\left(\Delta \mathrm{A} 660 \cdot \mu \mathrm{m} \cdot \mathrm{s}^{-1}\right)\right)$ increased in low oxidative area of TA of Acvr1b ${ }^{\mathrm{fl} / \mathrm{fl} l}$ :Tgfbr $1^{\mathrm{fl} / \mathrm{fl}}$ animals. (F) Increased number of Pax7 positive cells per myofibre and regenerating areas $(2.91 \%)$ were found in TA of Acvr1 ${ }^{\mathrm{fl} / \mathrm{fl}}:$ Tgfbr $1^{\mathrm{fl} / \mathrm{fl}}$ mice (scale bars $\left.=100 \mu \mathrm{m}\right) . \mathrm{N}=5-8$ mice. Results are presented as mean + 
SEM. *: $P<0.05$. Significant difference between individual groups is indicated by lines with a *. Single * indicates significant difference compared to all other groups.

Figure 2. Simultaneous knockout of both Acvrlb and Tgfbrl reduced mRNA expression of E3 ligase Murf-1and stimulated signalling for protein synthesis. (A) Normalised relative gene expression in non-injured muscle. (B) Western blot analysis of phosphorylated and total Akt and p70S6K in TA muscles. Results are presented as mean + SEM. N=5-8 mice. *: $P<0.05$. Significant difference between individual groups is indicated by lines with a *. Single * indicates significant difference compared to all other groups.

Figure 3. Immune response was slightly enhanced in muscle of $A c v r 1 b^{\mathrm{fl} / f \mathrm{fl}}: \operatorname{Tgfbr} 1^{\mathrm{fl} / \mathrm{fl}}$ mice. (A) Representative images of $\mathrm{H} \& \mathrm{E}$ and eMyHC staining of TA sections at 2 and 4 days after CTX injection (scale bars $=250 \mu \mathrm{m}$ ). (B) Scheme shows CTX injection in TA and sample collection. (C) Percentage of injury area was not significantly different between groups. (D) Relative gene expressions in TA in the absence (day 0) or presence of CTX injection after 2 and 4 days. Results are presented as mean + SEM. N=5-8 mice, $*: P<0.05$. Significant difference between individual groups is indicated by lines with a $*$. Single * indicates significant difference compared to all other groups.

Figure 4. Acvr1b ${ }^{\mathrm{fl} / f 1}:$ Tgfbr $1^{\mathrm{fl} / \mathrm{fl}}$ mice showed enhanced CSA of regenerating fibres and early enhanced expression of myogenic genes after acute injury. (A) IF staining images represent eMyHC positive myofibres 4 days after CTX injection (scale bars $=100 \mu \mathrm{m}$ ). (B) CSA of eMyHC positive myofibres in injured area increased in $A c v r 1 b^{\mathrm{fl} / f 1}: \operatorname{Tgfbr} 1^{\mathrm{fl} / \mathrm{fl}}$ mice compared to $A c v r 1 b^{\mathrm{fl} / f 1}$ and Tgfbr1 $1^{\mathrm{fl} / f 1}$ animals, while RI was decreased in both Acvr1b $\mathrm{b}^{\mathrm{fl} / f \mathrm{l}}$ and Tgfbr $1^{\mathrm{fl} / f 1}$ mice compared to controls. Relative gene expression in TA in absence (day 0) or presence of 
CTX injection after 2 and 4 days are presented. Results are presented as mean + SEM. N=5-8 mice, $*: P<0.05$. Significant difference between individual groups is indicated by lines with a *. Single * indicates significant difference compared to all other groups.

Figure 5. Relative mRNA expression levels of ECM components were enhanced in Acvr1b ${ }^{\mathrm{fl} / \mathrm{fl}}:$ Tgfbr $1^{\mathrm{fl} / \mathrm{fl}}$ mice. (A) Sirius Red staining shows collagen deposition in absence (day 0) or presence of CTX injection after 2 , and 4 days (scale bar $=100 \mu \mathrm{m}$ ). (B) Relative gene expression in TA muscle in absence (day 0) or presence of CTX injection after 2 and 4 days. Results are presented as mean + SEM. N=5-8 mice, $*: P<0.05$. Significant difference between individual groups is indicated by lines with a *. Single * indicates significant difference compared to all other groups.

Figure 6. Schematic diagram of the effects of single or combined muscle specific knockout of $T g f b r l$ and/or Acvrlb receptors on muscle hypertrophy, regeneration and expression of ECM components. (A) Myofibre size is not affected after individual knockout of Acvrlb or $T g f b r 1$, which indicates that these receptors have redundant effects on muscle size and that myostatin signals via both receptors to control muscle mass. Simultaneous knockout of both Acvrlb and Tgfbrl inhibits signalling of TGF- $\beta$, myostatin and activin A and stimulates protein synthesis via the Akt/mTOR/p70S6K pathway, while inhibiting protein breakdown through repression of Murf-1 levels, resulting in substantial muscle hypertrophy. (B) Upon acute injury, simultaneous knockout of combined Acvrlb and Tgfbrl accelerates early muscle regeneration, as observed by increased myogenic gene expression as well as increased CSA of regenerating myofibres. An increased number of SCs likely contributes to these effects. (C) Simultaneous myofibre specific knockout of Acvrlb and Tgfbrl induces mRNA 
bioRxiv preprint doi: https://doi.org/10.1101/2021.03.03.433740; this version posted March 6, 2021. The copyright holder for this preprint (which was not certified by peer review) is the author/funder. All rights reserved. No reuse allowed without permission.

expression of ECM components. These effects are likely caused by enhanced TGF- $\beta 1$ signalling in fibroblasts. 
bioRxiv preprint doi: https://doi.org/10.1101/2021.03.03.433740; this version posted March 6, 2021. The copyright holder for this preprint (which was not certified by peer review) is the author/funder. All rights reserved. No reuse allowed without permission.

Supplementary table 1 . Primer sequences for qPCR

\begin{tabular}{|c|c|c|c|}
\hline Primer & Sequences & Primer & Sequences \\
\hline Rps13 & $\begin{array}{l}\text { Forward: CACGTGGCTGAAGTTGACG } \\
\text { Reverse: CAGGATTACACCTATCTGGGAGG }\end{array}$ & Myh3 & $\begin{array}{l}\text { Forward: CGCAGAATCGCAAGTCAATA } \\
\text { Reverse: CAGGAGGTCTTGCTCACTCC }\end{array}$ \\
\hline Rpl27 & $\begin{array}{l}\text { Forward: AGCCGTCATCGTGAAGAACA } \\
\text { Reverse: GGGGATAGCGGTCAATTCCA }\end{array}$ & IdI & $\begin{array}{l}\text { Forward: ACCCTGAACGGCGAGATCA } \\
\text { Reverse: TCGTCGGCTGGAACACAT }\end{array}$ \\
\hline Tgfbrl & $\begin{array}{l}\text { Forward: CCTCGAGACAGGCCATTTGT } \\
\text { Reverse: AGACGAAGCAGACTGGACCA }\end{array}$ & $F g f-2$ & $\begin{array}{l}\text { Forward: AAGCGGCTCTACTGCAAGAA } \\
\text { Reverse: GTAACACACTTAGAAGCCAGCAG }\end{array}$ \\
\hline Acvrlb & $\begin{array}{l}\text { Forward: TGCTGCGCCATGAAAACATC } \\
\text { Reverse: TGCCCACAATCTCCATATGCA }\end{array}$ & Ctgf & $\begin{array}{l}\text { Forward: CCACCCGAGTTACCAATGAC } \\
\text { Reverse: GCTTGGCGATTTTAGGTGTC }\end{array}$ \\
\hline $\operatorname{Tg} f-\beta 1$ & $\begin{array}{l}\text { Forward: GCTGACCCCCACTGATACG } \\
\text { Reverse: CCTGTATTCCGTCTCCTTGGTT }\end{array}$ & Colla1 & $\begin{array}{l}\text { Forward: ATGTTCAGCTTTGTGGACCT } \\
\text { Reverse: CAGCTGACTTCAGGGATGT }\end{array}$ \\
\hline Mstn & $\begin{array}{l}\text { Forward: GAGAATGGCCATGATCTTGCTG } \\
\text { Reverse: CTTCTAAAAAGGGATTCAGCCCATC }\end{array}$ & Col3a1 & $\begin{array}{l}\text { Forward: AAGGACATCGAGGATTCCCTG } \\
\text { Reverse: AGCCCTCAGATCCTCTTTCAC }\end{array}$ \\
\hline Igflea & $\begin{array}{l}\text { Forward: GTGTTGCTTCCGGAGCTGTG } \\
\text { Reverse: CAATGTACTTCCTTCTGAGTC }\end{array}$ & $C d 68$ & $\begin{array}{l}\text { Forward: TCCCAACAAAACCAAGGTCCA } \\
\text { Reverse: } \quad \text { GGCTCTGATGTAGGTCCTGTTT }\end{array}$ \\
\hline$H g f$ & $\begin{array}{l}\text { Forward: GATTATTGCCCTATTTCCCGTTGTG } \\
\text { Reverse: TGGCACAGGATATTACAGGATGG }\end{array}$ & Cd163 & $\begin{array}{l}\text { Forward: CGGCCCCATGAAGAGGTATC } \\
\text { Reverse: GACGGTTGACCCAGTTGTTG }\end{array}$ \\
\hline$M g f$ & $\begin{array}{l}\text { Forward: GGAGAAGGAAAGGAAGTACATTTG } \\
\text { Reverse: CCTGCTCCGTGGGAGGCT }\end{array}$ & $I l-1 \beta$ & $\begin{array}{l}\text { Forward: GCCACCTTTTGACAGTGATG } \\
\text { Reverse: CTTCTCCACAGCCACAATGA }\end{array}$ \\
\hline Vegf & $\begin{array}{l}\text { Forward: CTGTAACGATGAAGCCCTGGAGTG } \\
\text { Reverse: GGTGAGGTTTGATCCGCATGATCT }\end{array}$ & Il-6 & $\begin{array}{l}\text { Forward: GGAAATGAGAAAAGAGTTGTGC } \\
\text { Reverse: GTACTCCAGAAGACCAGAGGA }\end{array}$ \\
\hline Pax 7 & $\begin{array}{l}\text { Forward: TCCATCAAGCCAGGAGACA } \\
\text { Reverse: AGGAAGAAGTCCCACACAG }\end{array}$ & Atrogin-1 & $\begin{array}{l}\text { Forward: AGACTGGACTTCTCGACTGC } \\
\text { Reverse: TCAGCTCCAACAACAGCCTTACT }\end{array}$ \\
\hline Myod & $\begin{array}{l}\text { Forward: CATCCAGCCCGCTCCAAC } \\
\text { Reverse: GGGCCGCTGTAATCCATCATGCC }\end{array}$ & Murf-1 & $\begin{array}{l}\text { Forward: CGTCCAGAGCGTGTGTCTCACTC } \\
\text { Reverse: GGGCTACCTTCCTCTCAAGTGC }\end{array}$ \\
\hline Myog & $\begin{array}{l}\text { Forward: CCCAACCCAGGAGATCATTT } \\
\text { Reverse: GTCTGGGAAGGCAACAGACA }\end{array}$ & & \\
\hline
\end{tabular}


bioRxiv preprint doi: https://doi.org/10.1101/2021.03.03.433740; this version posted March 6, 2021. The copyright holder for this preprint (which was not certified by peer review) is the author/funder. All rights reserved. No reuse allowed without permission.

Supplementary table 2. Antibodies for immunofluorescence staining

\begin{tabular}{|c|c|c|c|c|c|}
\hline \multirow[b]{2}{*}{ cocktail } & & \multirow[b]{2}{*}{ Reactivity } & \multicolumn{2}{|l|}{ Working } & \multirow{2}{*}{$\begin{array}{l}\text { Working } \\
\text { concentration } \\
(\mathrm{ug} / \mathrm{mL})\end{array}$} \\
\hline & Antibody & & $\begin{array}{l}\text { concentration } \\
(\mathrm{ug} / \mathrm{mL})\end{array}$ & Secondary Antibody & \\
\hline \multirow{2}{*}{1} & BAD-5-s & MHC-I & 1 & $\begin{array}{l}\text { Goat anti-Mouse Alexa Fluor® } 647 \\
\operatorname{IgG}_{2 b}(\mathrm{~A} 21242)\end{array}$ & 5 \\
\hline & SC-71 & MHC-IIA & 10 & $\begin{array}{l}\text { Goat anti-Mouse Alexa Fluor® } 488 \\
\operatorname{IgG}_{1}(\mathrm{~A} 21121)\end{array}$ & 5 \\
\hline \multirow{2}{*}{2} & BF-F3 & MHC-IIB & 1 & $\begin{array}{l}\text { Goat anti-Mouse Alexa Fluor® } 647 \\
\text { IgM (A21238) }\end{array}$ & 5 \\
\hline & 6H1 & MHC-IIX & 1 & $\begin{array}{l}\text { Goat anti-Mouse Alexa Fluor® } 488 \\
\text { IgM (A21042) }\end{array}$ & 5 \\
\hline & F1.652-s & $\begin{array}{l}\text { Embryonic } \\
\text { myosin } \\
\text { heavy chain } \\
(\mathrm{eMyHc})\end{array}$ & 20 & $\begin{array}{l}\text { Goat anti-Mouse Alexa Fluor® } 488 \\
\operatorname{IgG}(\mathrm{H}+\mathrm{L})(\mathrm{A} 11029)\end{array}$ & 5 \\
\hline & PAX7 & Pax7 & 4 & $\begin{array}{l}\text { Goat anti-Mouse Alexa Fluor® } 488 \\
\operatorname{IgG}(\mathrm{H}+\mathrm{L})\end{array}$ & 4 \\
\hline
\end{tabular}

Primary antibodies were purchased from the Developmental Studies Hybridoma Bank (DSHB, Iowa City, IA, USA), secondary antibodies were purchased from Invitrogen (Thermo Scientific, Waltham, MA, USA). 
A

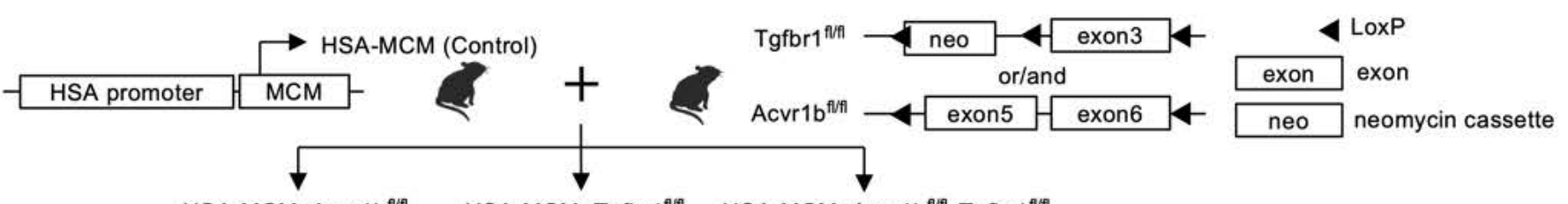

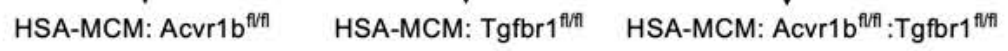

B

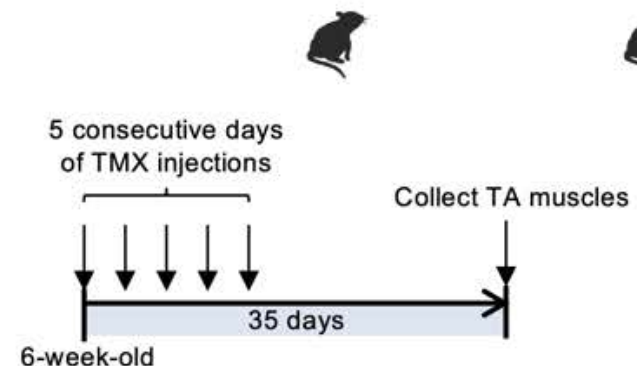

\section{C}

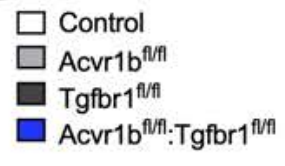

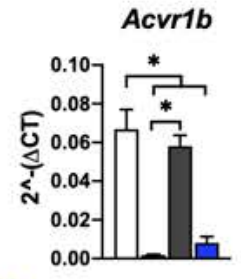

IIA/IB/DAPI

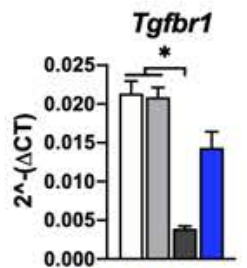

IIX/IDAPI

D

H\&E

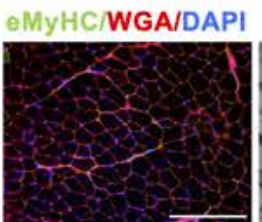

SDH
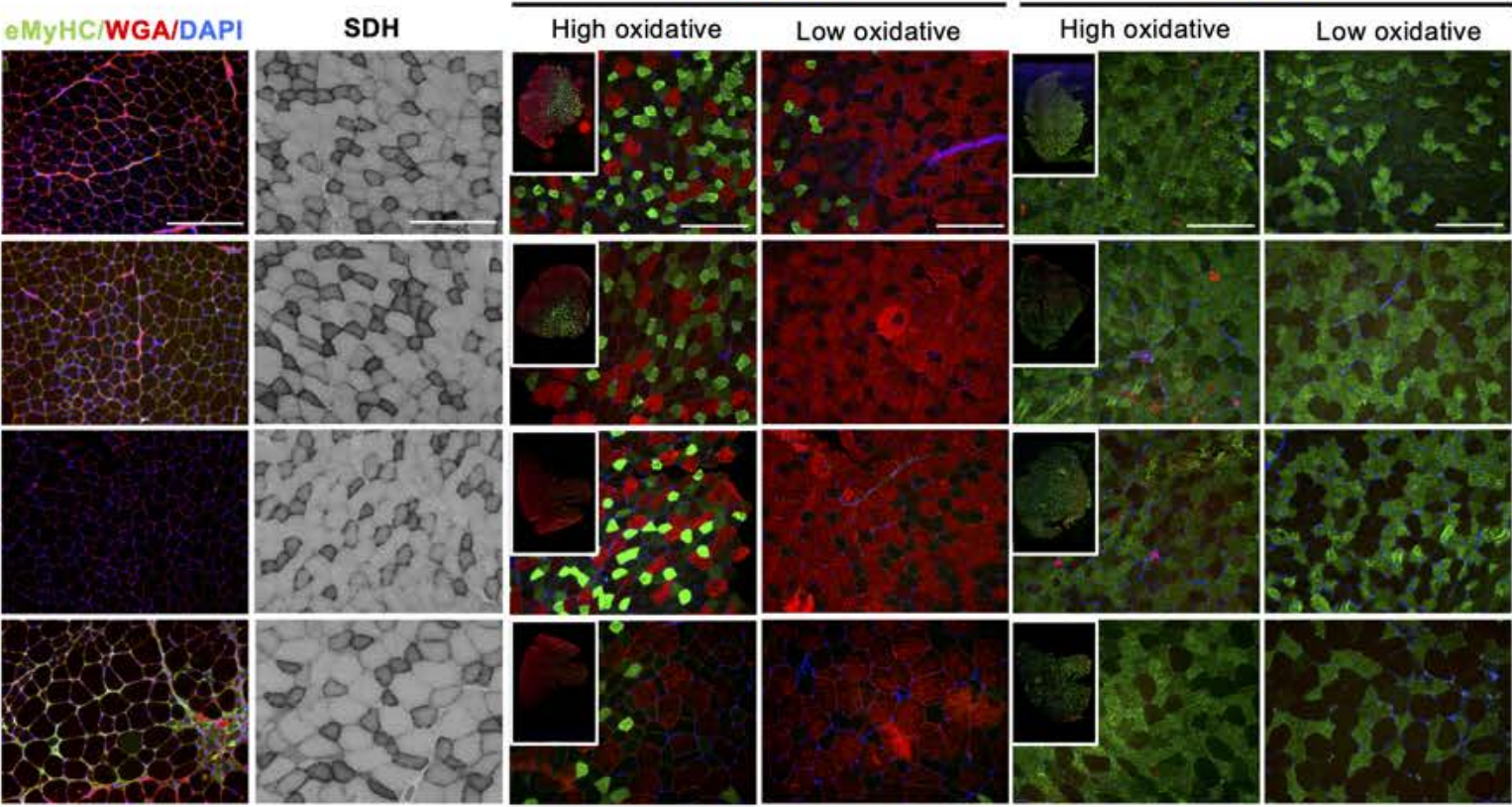

E
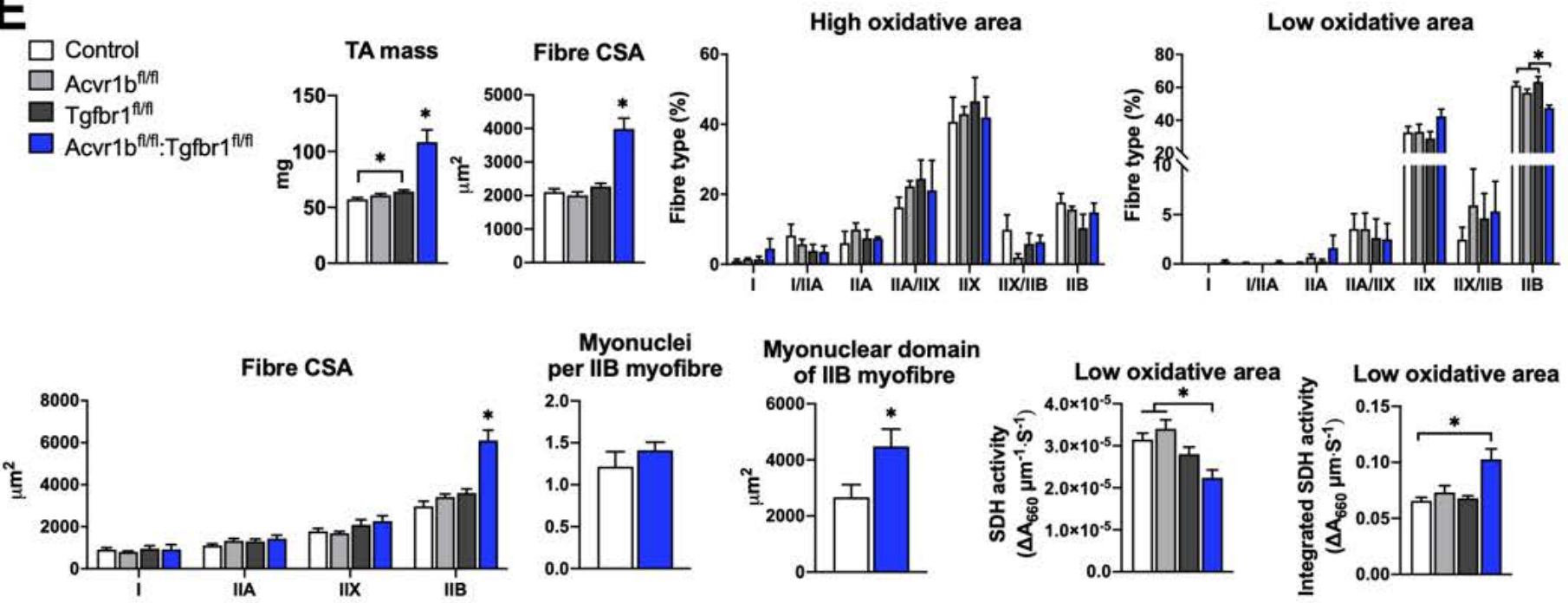

F
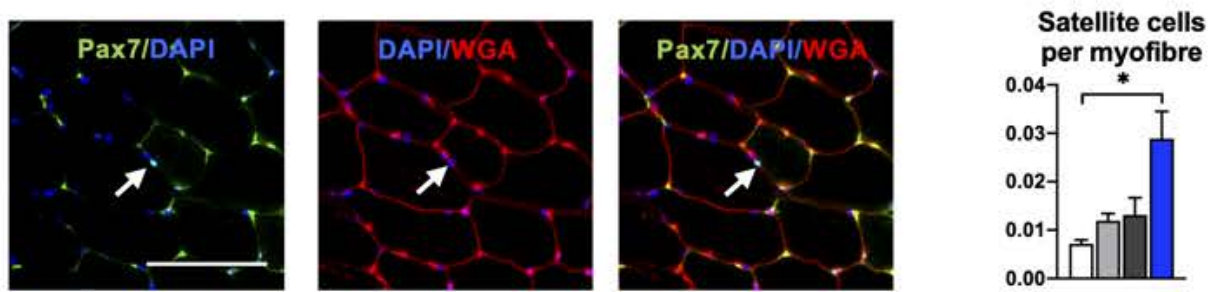

Regeneration area

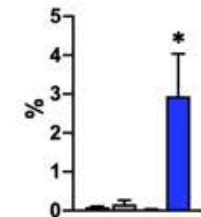


A
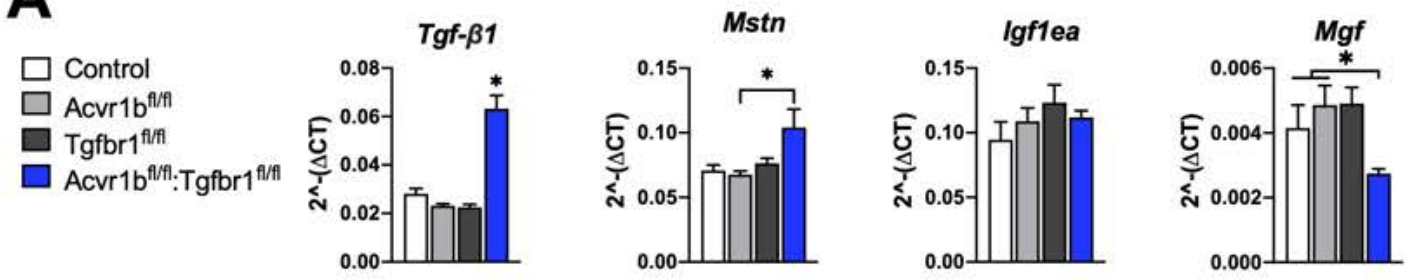

Fgf-2
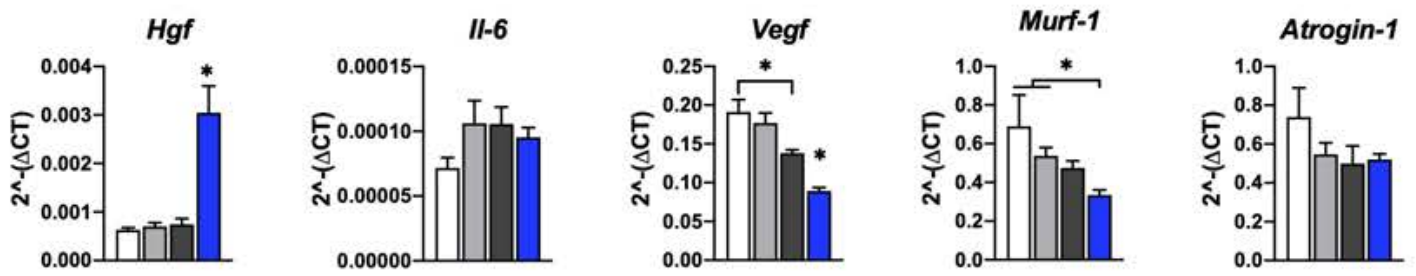

B
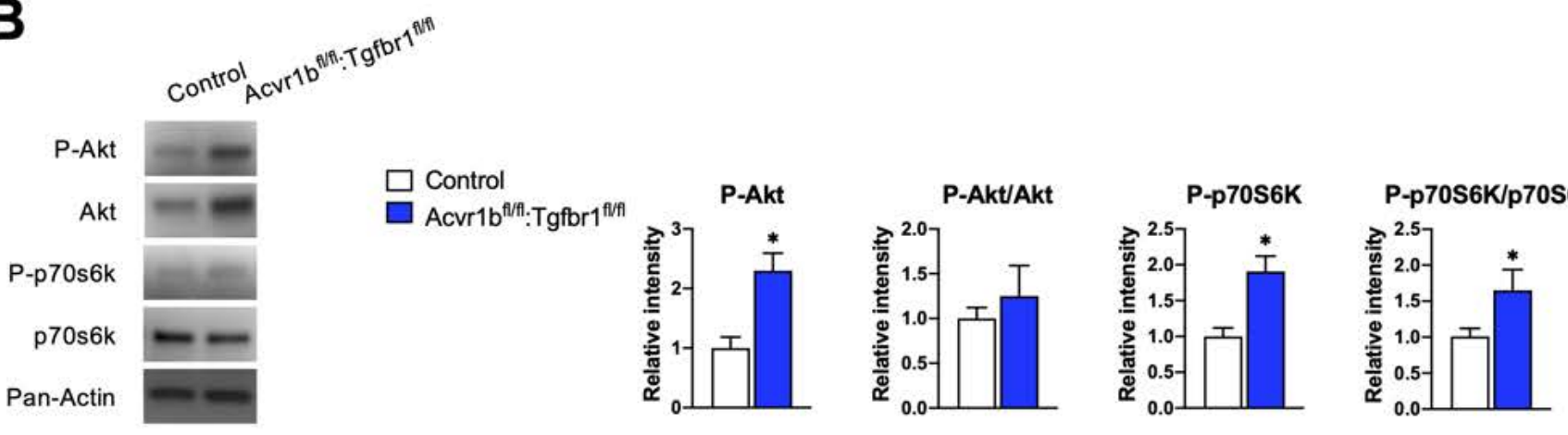
A

H\&E

eMyHC/WGADDAPI

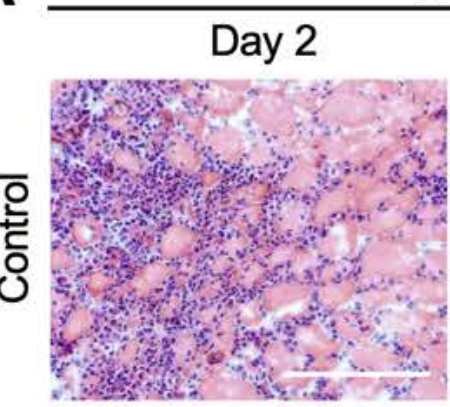

Day 4

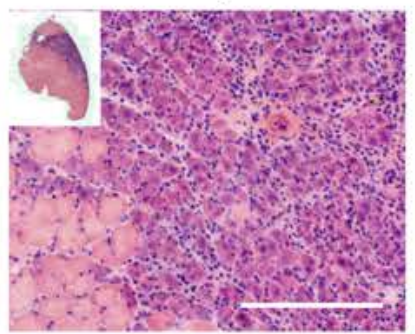

Day 2

Day 4
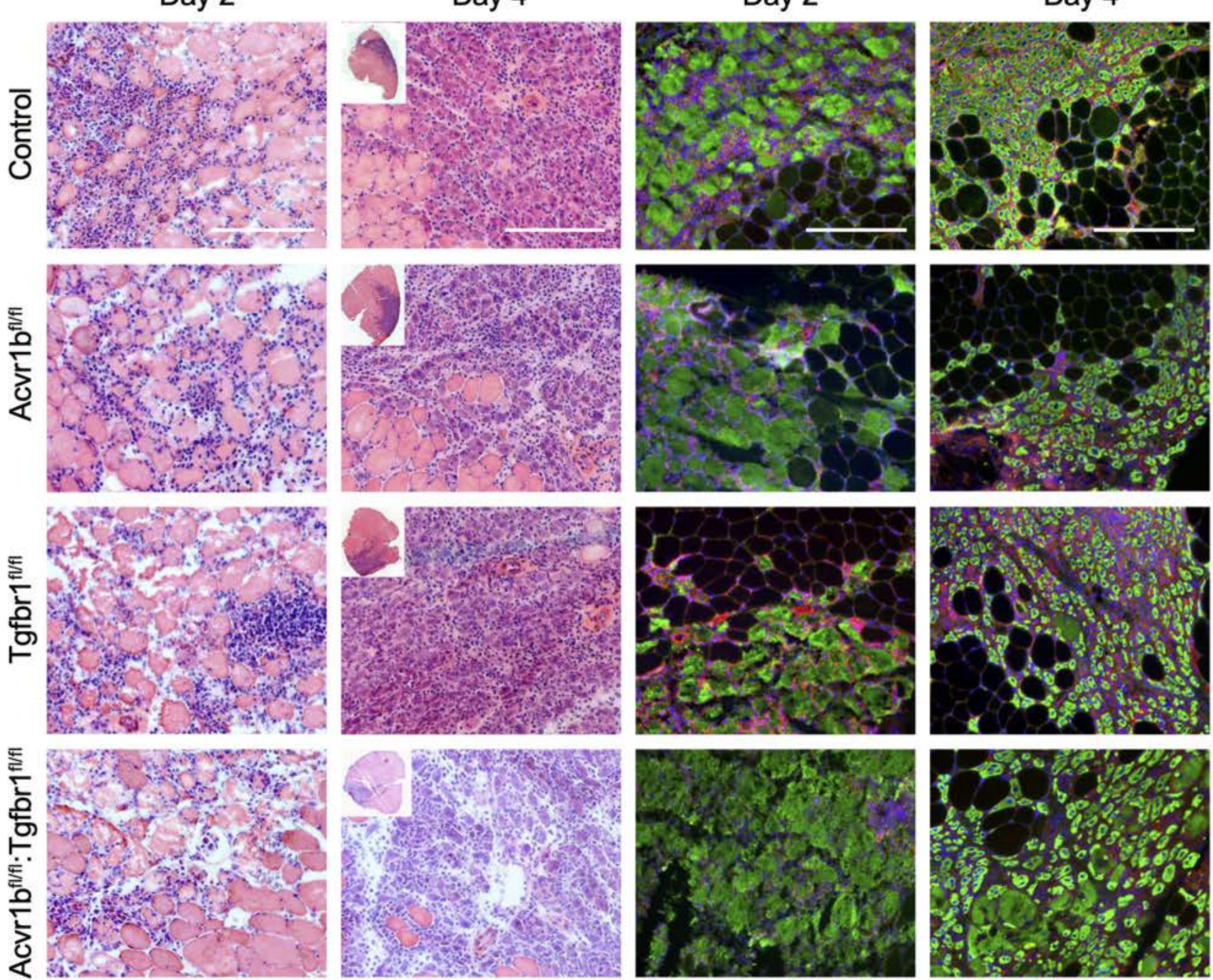

B

CTX injection (except

for group day 0 )

Collect TA muscles

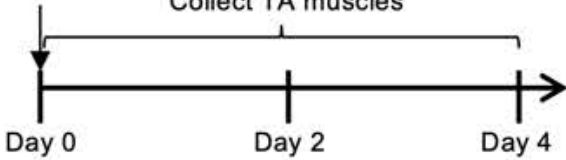

C

Injury size

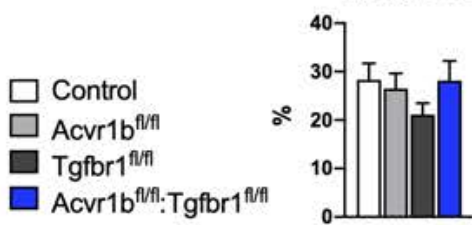

D
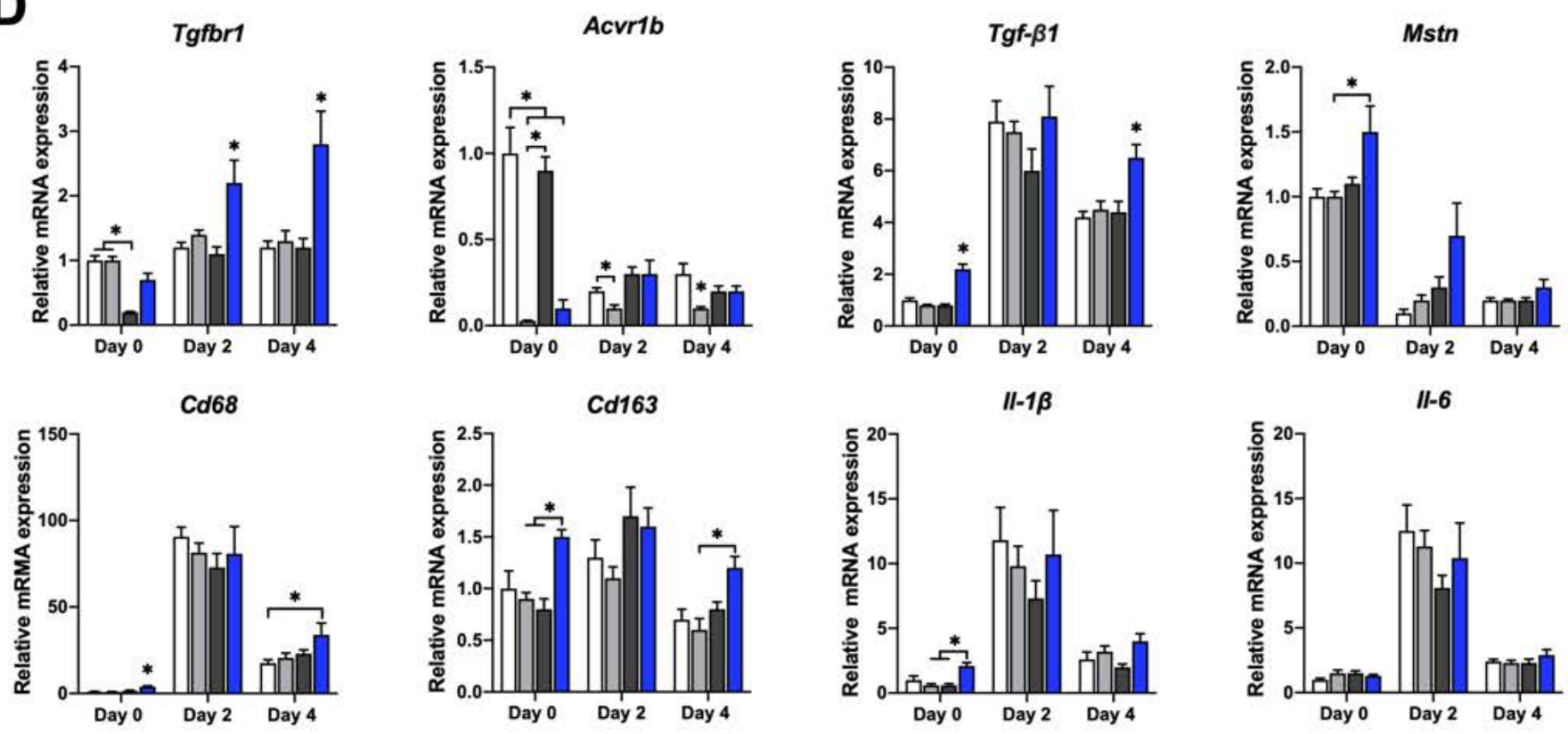

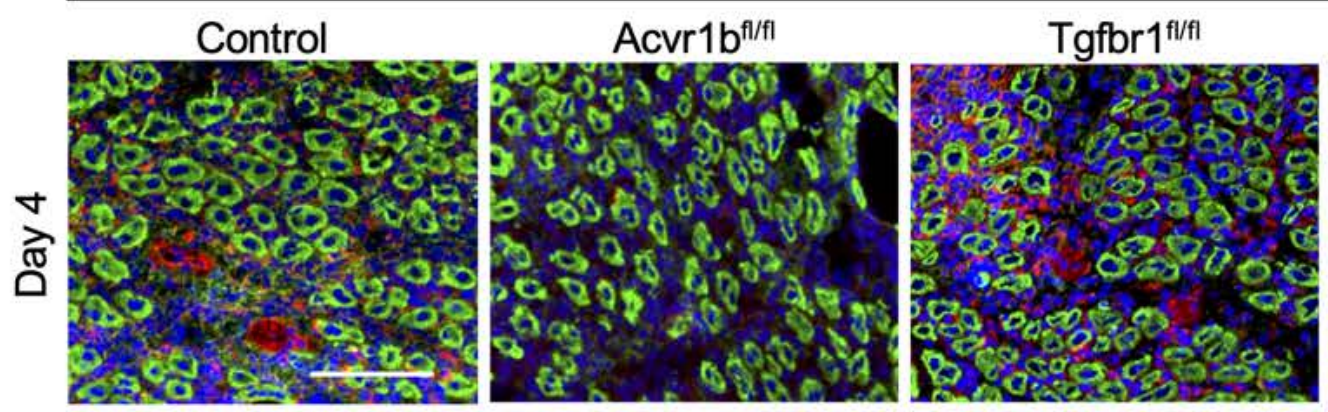

Acvr1 $b^{f / / f l}: T g f b r 1^{f / f f l}$

B

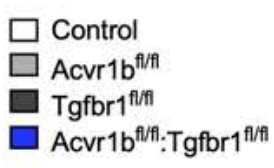

Fibre CSA Regeneration index
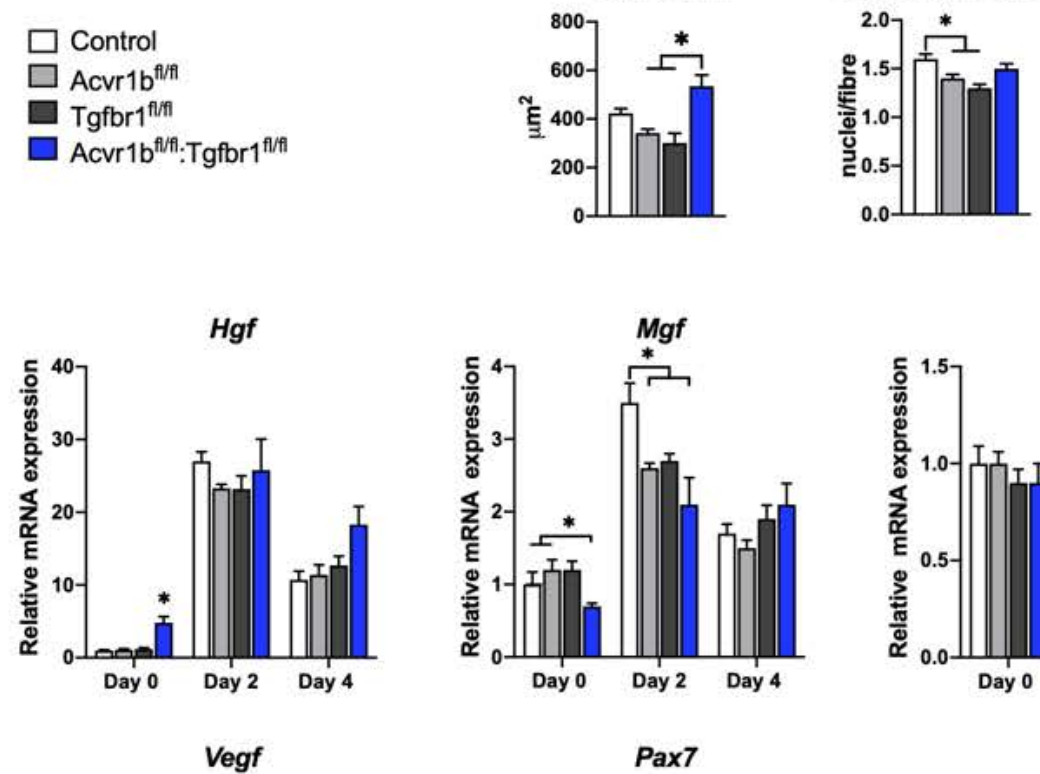

Fgf-2
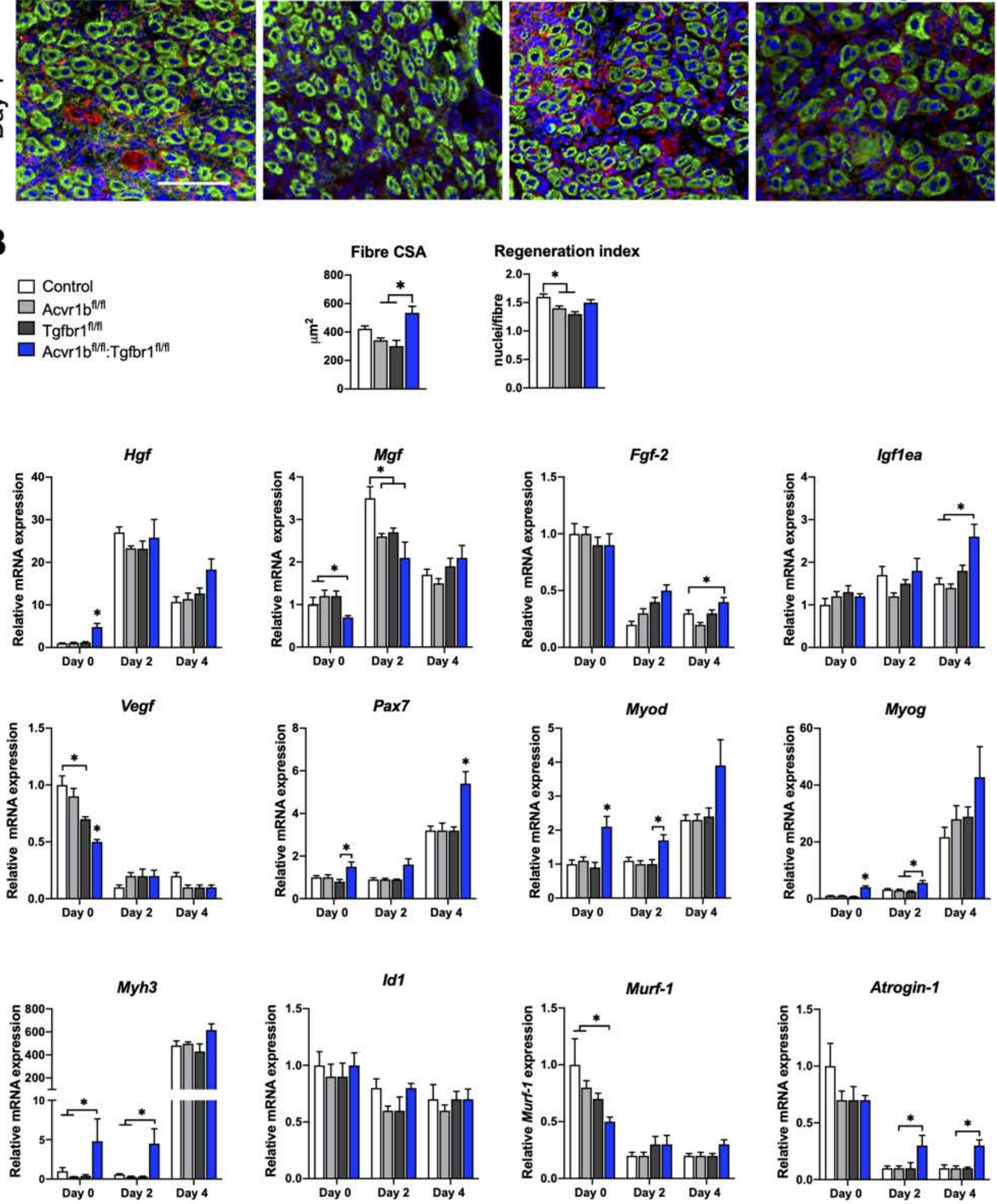
A

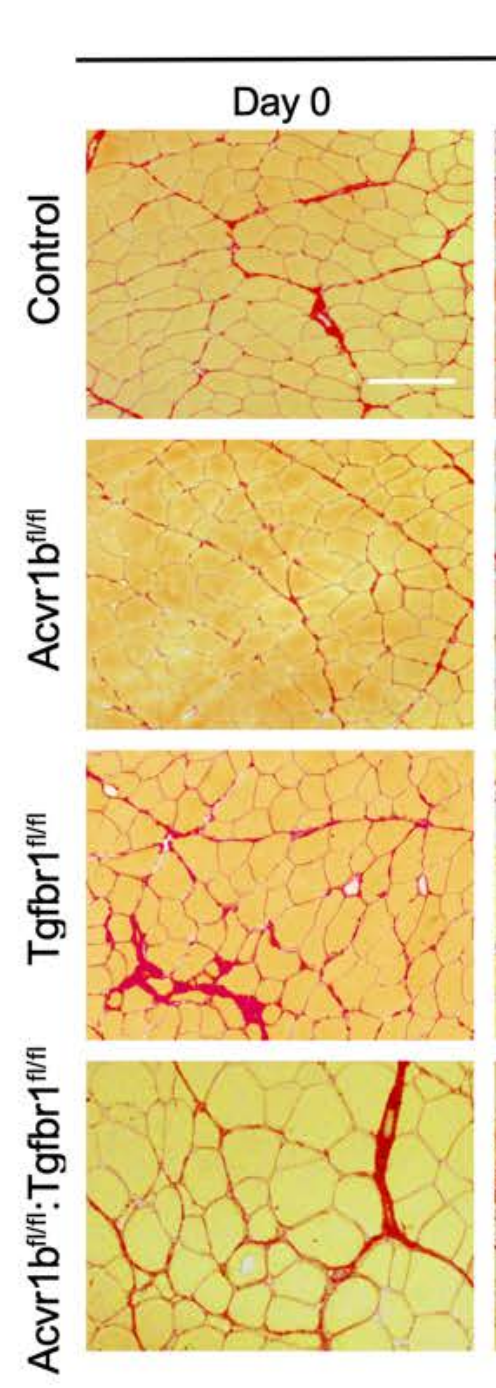

B

\section{Sirius Red}
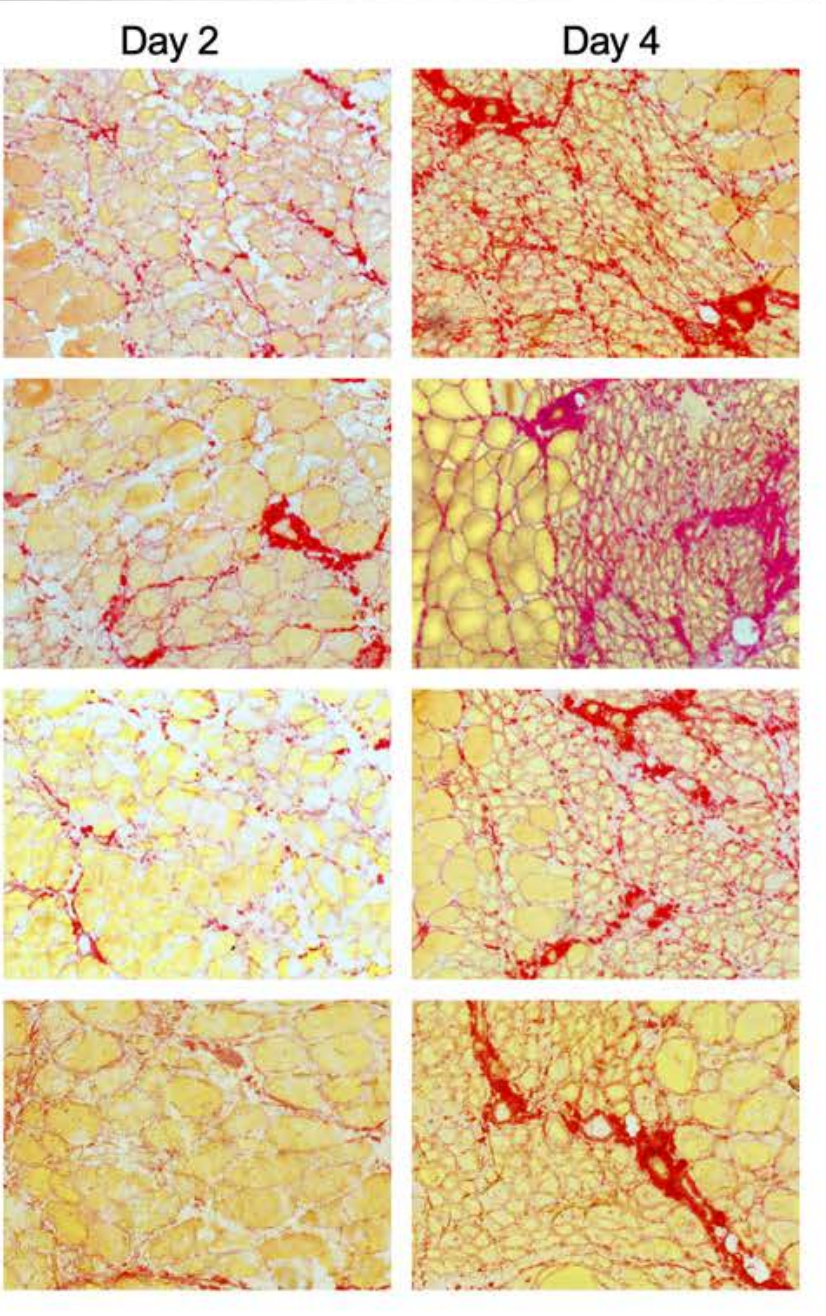
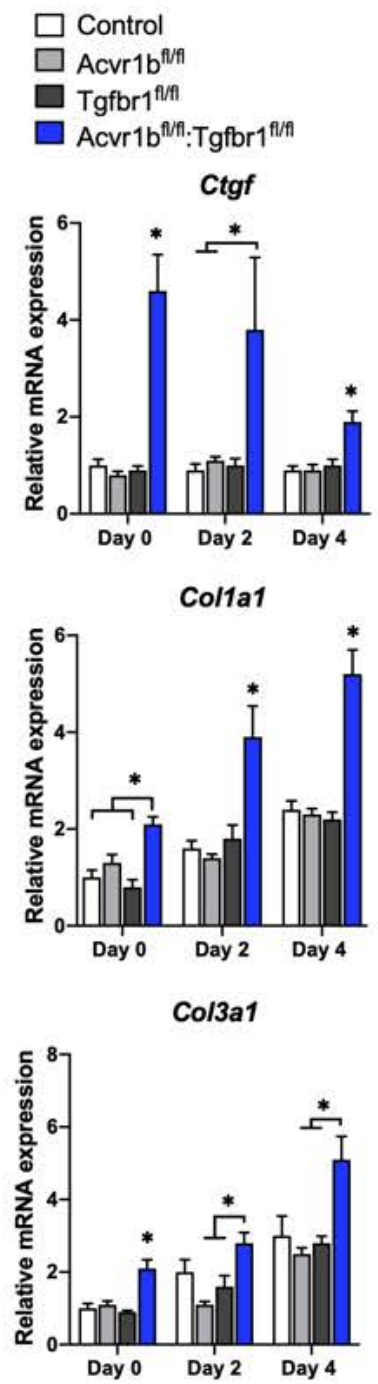

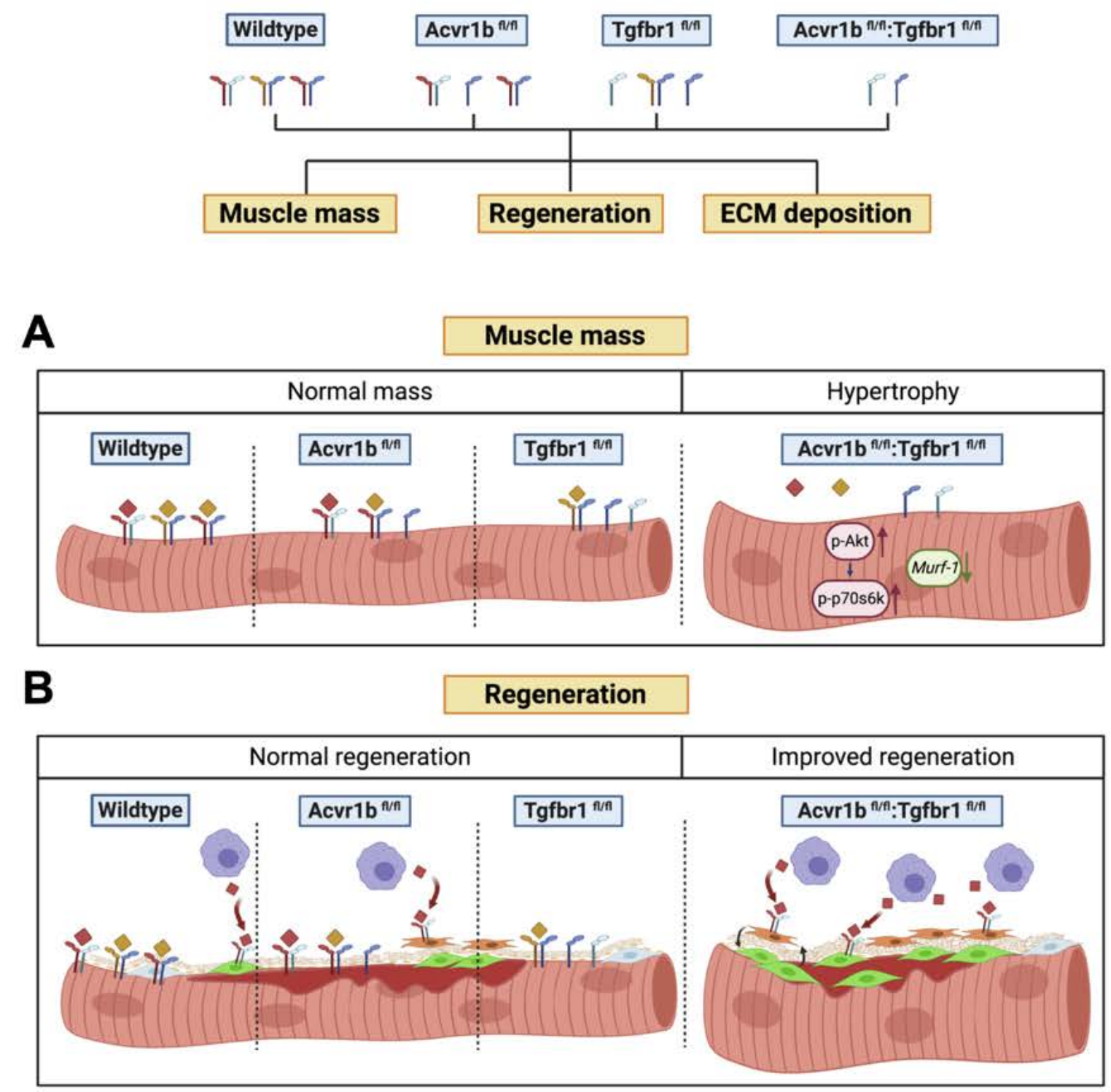

C

ECM deposition
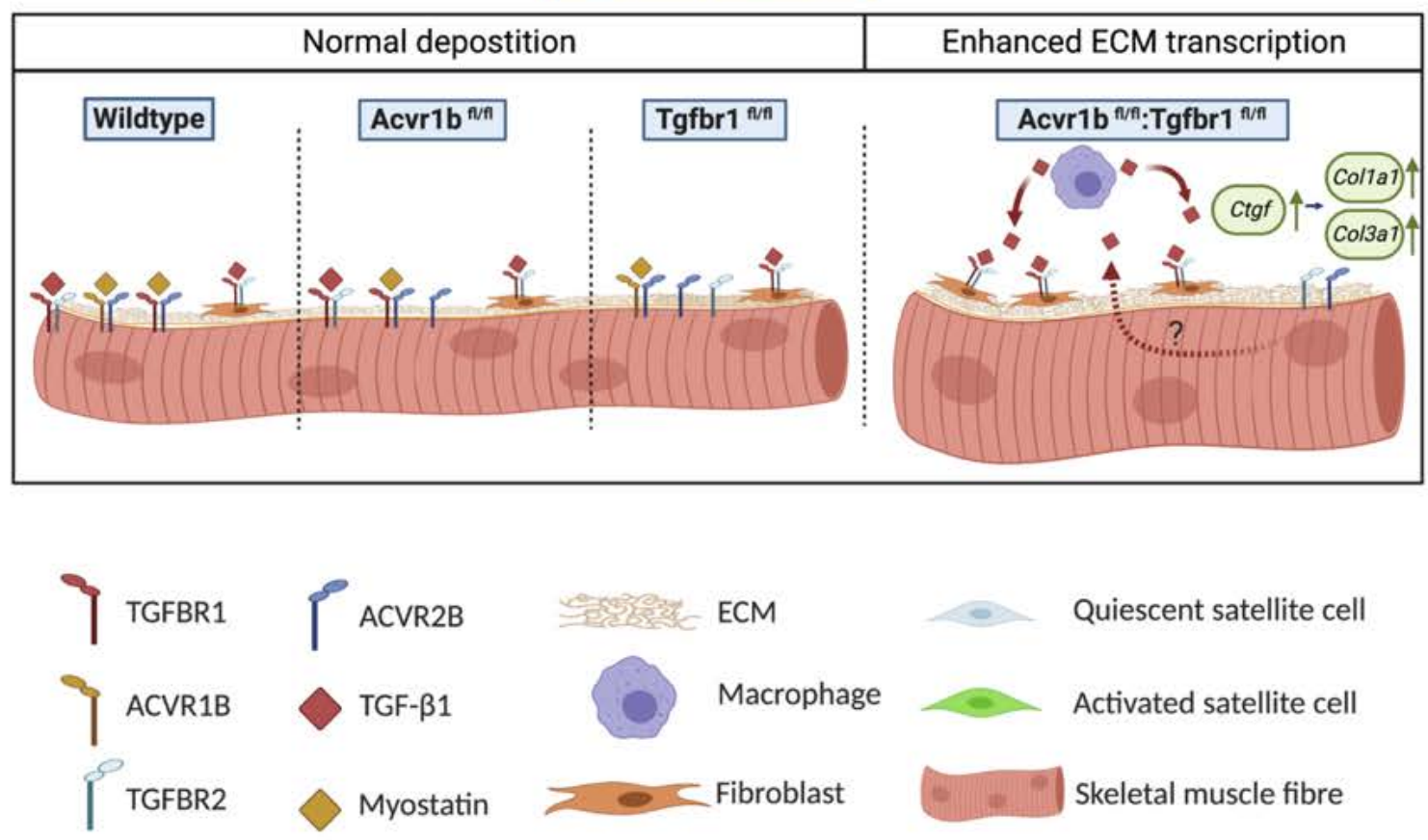